\title{
Hot weather and residential hourly electricity demand in Italy
}

Article

Accepted Version

Creative Commons: Attribution-Noncommercial-No Derivative Works 4.0

Alberini, A., Prettico, G., Shen, C. and Torriti, J. (2019) Hot weather and residential hourly electricity demand in Italy. Energy, 177. pp. 44-56. ISSN 0360-5442 doi: https://doi.org/10.1016/j.energy.2019.04.051 Available at https://centaur.reading.ac.uk/83169/

It is advisable to refer to the publisher's version if you intend to cite from the work. See Guidance on citing.

To link to this article DOI: http://dx.doi.org/10.1016/j.energy.2019.04.051

Publisher: Elsevier

All outputs in CentAUR are protected by Intellectual Property Rights law, including copyright law. Copyright and IPR is retained by the creators or other copyright holders. Terms and conditions for use of this material are defined in the End User Agreement.

\section{www.reading.ac.uk/centaur}

\section{CentAUR}

Central Archive at the University of Reading

Reading's research outputs online 


\title{
Hot Weather and Residential Hourly Electricity Demand in Italy
}

\author{
by \\ Anna Alberini, Giuseppe Prettico, Chang Shen, and Jacopo Torriti ${ }^{1}$
}

Last revision: 28 February 2019

Last revision by: Anna Alberini

\begin{abstract}
Concerns about climate change, pollution and energy security have prompted policies aiming at replacing fossil fuels (in heating and cooling, and transportation) with electricity, presumably generated from renewable sources. Climate change itself is expected to increase the demand for cooling in buildings, which is generally met with electricity-powered air conditioning. We use hourly electricity demand from a sample of Italian residences over a full year to examine how sensitive residential demand is to temperature. Our regression model includes a rich set of household-by-time fixed effects to control for dwelling characteristics and equipment, family composition, work and business schedules, demand for lighting, and seasonal habits other than temperature. These allows us to separate the effect of temperature from the demand for lighting and from other seasonal effects that may be correlated with temperature, but are not temperature. We find that demand stays within a relatively narrow range (and is thus relatively flat) up to temperatures of about $24.4^{\circ} \mathrm{C}$, and increases sharply with temperature thereafter. We find that temperature accounts for a very small share of daily electricity demand. Only on exceptionally hot summer days can temperature account for $12 \%$ of hourly electricity use.
\end{abstract}

Keywords: residential electricity consumption; temperature and electricity load; climate change.

\footnotetext{
${ }^{1}$ Alberini is a professor at AREC, University of Maryland, College Park, USA. Email: aalberin@umd.edu. Prettico is a research fellow and project officer at the Joint Research Centre, Dir. C Energy Transport and Climate C3, Ispra, Italy. Email: Giuseppe.prettico@ec.europa.eu. Shen is a graduate student at AREC, University of Maryland, College Park, USA. Email: cshen1 @ terpmail.umd.edu. Torriti is a professor in the School of the Built Environment at the University of Reading, UK. Email: j.torriti@ reading.ac.uk.
} 


\section{Introduction}

The power generation sector is a major contributor to greenhouse gas emissions that trigger climate change (IPCC, [1]). In the United States alone, in 2016 electricity generation was responsible for a total of 1,809.25 million metric tons of carbon dioxide $\left(\mathrm{CO}_{2}\right){ }^{2}$ or approximately $36 \%$ of the country's total $\mathrm{CO}_{2}$ emissions. ${ }^{3}$ Climate policy and the push towards renewables will affect this industry heavily, but the de-carbonization of the energy sector is in turn likely to be meaningfully affected by the changes in electricity demand induced by climate change (Tobin et al., [2]). Cooling is the fastest growing energy service in buildings, having doubled globally since the beginning of the $21^{\text {st }}$ Century (International Energy Agency, [3]). Air conditioners and electric fans already account for about one fifth of the total electricity in buildings, and the demand for electricity for heating will presumably decrease at many locales.

How does a changed climate—a warmer climate, in most places — affect electricity demand? Brown et al. [4] summarize earlier studies, noting that it is unclear which is a better predictor of electricity demand - temperature or heating/cooling degree days — and whether this relationship follows a U shape with a flat bottom or a sharp V. Auffhammer et al. (2017) use daily data from the balancing authorities in the United States, covering a total of 166 load zones, from 2006 to 2014, and find that while in certain zones (e.g., ERCOT, the Texas independent system operator), the temperature-load relationship is symmetric around $21^{\circ} \mathrm{C}$, for others on the East Coast loads grow much more sharply as the temperature rises above $21^{\circ} \mathrm{C}$. Franco and Sanstad [6] and Khanna [7] conclude that annual electricity demand in California can be

\footnotetext{
${ }^{2}$ See

https://www3.epa.gov/climatechange/ghgemissions/inventoryexplorer/\#electricitygeneration/allgas/source/current.

${ }^{3}$ In 2016 the US emitted a total of 5,011.69 million tons of CO2

(http://edgar.jrc.ec.europa.eu/overview.php?v=CO2andGHG1970-2016\&sort=des8).
} 
expected to increase by $0.8-17.8 \%$ and by $15 \%$, respectively, relative to the $1961-1990$ base period (depending on the model, SRES scenario, and period) over the course of the century.

A recent study by Wang and Bielicki [8] analyzes ten years of aggregated (i.e., all sectors) hourly electricity load data to estimate the relationship between electricity demand and meteorological conditions in the northeastern United States. It finds that there is a $\sim{ }^{\circ} \mathrm{C}$ "comfort zone" where electricity loads are less sensitive to temperature. Electricity loads are linearly sensitive to temperature when this is either below the lower comfort zone breakpoint or above the higher comfort breakpoint. ${ }^{4}$

Studies for the European Union have sought to predict electricity loads under a variety of climate change realizations. Damm et al. [11] predict total annual electricity consumption to diminish for all countries (except for one: Italy) due to the milder winters, which are not fully offset by the increased demand for cooling in the summer. By contrast, in Italy the relationship between temperature and electricity demand is shaped as a very sharp V, and Italy is the one country that is predicted to experience a net increase in electricity usage $(+0.5 \%)$, driven primarily by the increased demand for cooling. Wenz et al. [12] arrive at similar findings, which they characterize as a "north-south polarization" in energy demand.

This earlier literature has econometrically estimated the relationship between electricity load and temperature using total aggregated demand by all users - the industrial, commercial, and residential sectors - and thus has been unable to empirically separate the potentially different sensitivities to increases in the average global temperature across or within these groups of

\footnotetext{
${ }^{4}$ Among other things, Wang and Bielicki [8] examine the role of wind speed and dew point, and whether consecutive days of hot weather matter. Ahmed et al. [9] use stepwise regression techniques to investigate which weather variables are redundant for degree days. Jiang et al. [10] examine the effect of a cold wave in China on heating demand, finding that only the more developed areas saw a change in heating area consumption per floor area when heating degree days (their measure of cold weather and hence heating demand) increased.
} 
customers. Alternatively, previous studies have used model-based approaches to build bottom-up estimates of the change in electricity usage under future climate scenarios, as in Dirks et al. [13], whose approach is strictly based on the existing stock of buildings in the United States, and Afshari and Friedrich (2017), who modelled urban energy systems using hourly electricity demand and weather measurements. The literature analyzing the relationship between temperature and aggregate energy demand — consisting of industrial, commercial, and residential sectors - comprises a number of empirical studies. ${ }^{5}$

There are fewer empirical studies focusing on the relationship between temperature and electricity demand in the residential sector only. Heterogeneity across households is a potentially important issue when examining residential energy demand as a function of outside temperature (Birt et al. [15]; Mirasgedis et al. [16]). Summerfield et al. [17]) examine daily energy delivered to a large sample of UK homes between 2008 and 2010, where energy delivered is expressed in $\mathrm{kWh}$ and includes both gas (used for space heating, cooking and hot water) and electricity, with gas accounting for the majority of it. They define the power-temperature gradient (PTG) as the slope of the linear regression of daily energy delivered on average outside temperature when such temperature is between 0 and $15^{\circ} \mathrm{C}$. The PTG is thus the expected decline in energy delivered as the average temperature increases by $1^{\circ} \mathrm{C}$. The PTG is estimated separately for each dwelling and is found to vary across dwelling types (e.g., single-family home, flat in a building, etc.) and to increase with the number of rooms and the age of the dwelling, but not, once these are controlled for, with the number of occupants. The homes with the largest PTG are also the ones with the most pronounced fluctuations in load within the day, on cold (average temperature $\left.0^{\circ} \mathrm{C}\right)$, moderate $\left(8^{\circ} \mathrm{C}\right)$ and mild $\left(18^{\circ} \mathrm{C}\right)$ days.

\footnotetext{
${ }^{5}$ For a review, see Wang and Bielicki [8].
} 
The aim of this paper is to explore the relationship between temperatures and hourly residential electricity demand. We use hourly electricity load data from a sample of homes in Italy, merged with temperature data. For context, ARERA [18] reports that the total electricity consumption in 2011 in Italy was 311.6 TWh, and that residential consumption accounted for $22.34 \%$ of this figure.

Our work differs from earlier studies in at least four respects. First, we focus on residential loads. Second, we seek to separate the effect of temperature from that of other seasonal factors that may be correlated with temperature, but are not temperature. For example, in the summer people may need to use more electricity for cooling purposes but less for lighting, as there are more hours of daylight (Jylhä et al. [19]). They may also spend more time outside of the house or away from home, which would imply less demand for electricity. We account for the different behaviors, which in turn affect loads, using a rich set of household-by-time fixed effects. We also account for whether it is completely dark or otherwise, which depends on the time of the day and varies across seasons and locations.

Third, since our data are at the household level for each hour and each day of the year 2011, we examine whether the effect of temperature is different for different households, depending on their income, house size, location and ownership of appliances and electric devices. Finally, rather than running global circulation models under alternate scenarios (e.g., RCP2.6, RCP4.5, etc.), downscaling them to the local level, and predicting electricity demand at the resulting temperatures (which means applying temperature changes expected to occur midcentury to the current stock of housing, energy efficiency technology and behaviors), we conduct a somewhat different exercise. We use the results from our regressions to predict what the demand would have been, had the temperatures in the summer of 2011 been what they were in 
the summer of 2003, when an unprecedented heat wave swept across all of Europe, causing difficulties in the generation sector, and even more important, leading to tens of thousands premature deaths among the population of several European countries (Foulliet et al. [20]). ${ }^{6}$ We also predict what the usage would have been if the temperatures in our 2011 sample had been raised systematically by $1^{\circ} \mathrm{C}$.

Briefly, we find that, even with our rich set of fixed effects and controls, the demand for electricity does rise sharply as the outdoor temperature increases above $24.4^{\circ} \mathrm{C}$, but remains within a narrow range for temperatures below that. The " $\mathrm{J}$ " shape of the relationship between electricity usage and temperature is robust to several checks, and, importantly, the slope with respect to temperature is virtually the same across income groups. We also find that the temperature itself explains on average a relatively low share of load (roughly $2.9 \%$ in 2011). We show that holding consumption behaviors and equipment the same as 2011 , on the warmest 2003-level days, load would have increased up to $12 \%$ of total daily usage.

\section{Data and Methods}

\subsection{The Data}

We have electricity consumption collected by smart meters at 15-minute intervals from a sample of 396 homes in Italy. These meter readings cover an entire year, 2011, from January $1^{\text {st }}$ to December $31^{\text {st }}$. This sample was provided to us by the Italian National Regulatory Authority (ARERA), and is representative of the geographic distribution of the population, as shown in

\footnotetext{
${ }^{6}$ See https://www.metoffice.gov.uk/learning/learn-about-the-weather/weather-phenomena/case-studies/heatwave and http://www.grid.unep.ch/products/3 Reports/ew heat_wave.en.pdf.
} 
table 1 . For context, during our study period the majority $(80 \%)$ of the residential customers were served under a regulated price regime (ARERA [18]).

For each household, in addition to the municipality and region of residence, we also have information about the number of white goods owned, ${ }^{7}$ the total number of electrically operated devices owned (including TVs, computers, and others), whether hot water is supplied by one or more electric water heaters, and the approximate size of the dwelling (in square meters, banded into 10-square-meter intervals). We also know the number of household members and have a rough indicator of household income (5 categories, ranging from "very low" to "very high"). Descriptive statistics of these variables in the sample are reported in tables 2, 3 and 4.

We do not have information about the type of heating and cooling systems used in each dwelling, but the Italy Residential Energy Consumption Survey (RECS), which was conducted in 2013 , reports that $79.81 \%$ of the homes in Italy use natural gas as their only or main heating fuel. ${ }^{8}$ Regarding cooling, RECS indicates that about $27.60 \%$ of the homes in Italy have some form of air conditioner - either a heat pump (19\% of the total) or central, individual-room, or movable air conditioners. (This definition excludes electric fans.)

Some information about cooling devices in Italian homes is also available from the Household Budget Survey (HBS), which is conducted annually on independent cross-sections from the population. ${ }^{9}$ The HBS from each year from 2004 to 2016 shows that the penetration of cooling devices increased at an annual rate of 1.6-2\%.

In this paper we examine the electricity demand and its responsiveness to temperature, so we merged the household load records with temperature. We obtained temperature data for Italy

\footnotetext{
7 "White goods" is a term that refers to refrigerators, freezers, clothes washing machines and tumble dryers (https://www.ademe.fr/energy-efficiency-of-white-goods-in-europe-monitoring-the-market-with-sales-data).

${ }^{8}$ See https://www4.istat.it/it/archivio/203344.

${ }^{9}$ See https://www.istat.it/en/archive/180353.
} 
in 2011 from the Modern-Era Retrospective Analysis for Research and Applications version 2 (MERRA-2).${ }^{10}$ MERRA-2 is a global atmospheric reanalysis produced by the NASA Global Modeling and Assimilation Office (GMAO) that spans the satellite observing era from 1980 to the present and has a resolution of $0.5^{\circ} \times 0.625^{\circ}$ (approximately $50 \mathrm{~km} \times 65 \mathrm{~km}$ ). MERRA-2 provides atmospheric temperature at different pressure levels every 3 hours. We assign temperature to each location after matching the town or city each household lives in with its geographic coordinates and elevation (and hence pressure). Table 5 and figure 1 summarize information about the mild climate of Italy: the average temperature is $22^{\circ} \mathrm{C}$, and the distribution of hourly temperature is bimodal.

Turning to electricity, as shown in table 5 the average hourly load per household is approximately $0.3 \mathrm{kWh}$, which is equivalent to a little over $7 \mathrm{kWh}$ a day, or $2622 \mathrm{kWh}$ a year. This is in line with the average consumption levels (about $2700 \mathrm{kWh} / \mathrm{year}$ ) generally used by the Regulator to compute expenditure on electricity bills and the impacts of various pricing or other supply policies. ${ }^{11}$ Meter readings equal to zero account for $0.69 \%$ of the sample. We attribute them to either absences from home or outages. This is consistent with the fact that in Sardinia (the second largest island of Italy, and both a vacation destination with vacation homes likely vacant for part of the time as well as an area with grid difficulties) they account for up to about $3 \%$ of the observations.

As expected, electricity usage does vary widely throughout the day. Figure 2 shows that during the week consumption is lowest in the early morning, then rises as people get up to go school or work, or simply go about their daily routine. There is an early afternoon peak between

\footnotetext{
${ }^{10}$ See https://gmao.gsfc.nasa.gov/reanalysis/MERRA-2/.

${ }^{11}$ ARERA [21] reports that household consumption was $2700 \mathrm{kWh} /$ year in 2011, and had fallen to $2400 \mathrm{kWh}$ by 2014.
} 
13:00 and 15:00, and a much more pronounced evening peak between 19:00 and 21:00. At the evening peak, usage is about three times as much as large as lowest level, which is observed between 4:00 and 5:00am.

Figure 2 also contrasts weekday patterns with weekend patterns. On the weekends, the morning usage increase is a little delayed compared to that on weekdays, presumably as a result of a morning schedule that for many people is not associated with work activities. Consumption also remains somewhat higher throughout the day, as people spend more time at home and engage in energy-using household chores, and the evening peak is lower. These patterns are consistent with our expectations.

Figure 3 displays the average daily consumption by average daily temperature. Usage exhibits only minor fluctuations as the average temperature is below $5^{\circ} \mathrm{C}$, hits a plateau between 5 and $10^{\circ} \mathrm{C}$, and then declines as the average temperature rises, reaching its minimum between 17.5 and $20^{\circ} \mathrm{C}$, and rising sharply thereafter. We had expected electricity usage to be high when the weather is cold, in part because people spend more time inside and there are fewer hours of daylight, and in part because electricity may be used as the main or as a secondary heating fuel. ${ }^{12}$ In practice, however, electricity usage does not increase sharply as the temperature drops. Rather, it increases sharply as the temperature rises, presumably as more power is needed to run cooling devices. In the remainder of this paper, we estimate the exact extent of this increase and examine its impact on electricity demand under alternate hot weather scenarios.

\footnotetext{
${ }^{12}$ In practice, the Italy Residential Energy Consumption Survey of 2013 and the Italy HBSs since at least 2004 confirm that natural gas is the main heating fuel used in the majority (two-thirds or more) of the Italian homes. Electricity is not as frequently used, and only recently have a number of policies promoted high-efficiency heat pumps for heating and cooling purposes (see http://www.enea.it/it/seguici/pubblicazioni/pdfvolumi/2018/detrazioni-2018-executivesummary-en.pdf).
} 


\subsection{The Model}

Earlier studies have focused on the heterogeneity of electricity demand and how demand, and demand responsiveness to electricity price, depends crucially on the stock of energy-using durables in the home (McFadden et al. [22]; Reiss and White [23]). Our dataset contains information about the number of "white goods" and electrical appliances in the home, but does not tell us what specific appliances they are, their vintages and/or energy efficiency levels. We do know the home's approximate size, which is a major determinant of electricity demand (Alberini et al. [24]).

For these reasons, we specify a regression equation that contains a rich set of fixed effects to capture the unobserved heterogeneity across households and over time, plus terms that capture the effect of temperature:

$$
E_{i s}=F E(i, s)+\sum_{j=1}^{J} T_{j} \delta_{j}+\varepsilon_{i s}
$$

where $E_{i s}$ denotes the electricity demand of household $i$ during a suitably defined period $s$ (see below), $F E(i, s)$ denotes a set of household- and time-specific fixed effects (described in detail below), while we let the effect of temperature be captured by a set of dummies denoting whether or not the temperature at time $s$ falls in a specified interval. This approach is very flexible, in that it does not impose any functional form (whether linear, piecewise linear as in Wang and Bielicki [8], or polynomial) on the relationship between temperature and electricity load. It is also less sensitive to the presence of outliers than a polynomial of order three or higher is likely to be. Its only assumption is that the relationship is linear within the very small temperature range within each "bin" $j$.

Our experience (e.g., Alberini et al. [25]; Alberini et al. [26]) is that household electricity loads are affected by temperature, but temperature accounts only for a small share of the total 
variability in loads. For example, in Alberini et al. [26] we found that the household fixed effects alone accounted for $73 \%$ of the variation in monthly household electricity usage in Western Ukraine. Adding time fixed effects common to all households raised the regression $\mathrm{R}^{2}$ to 0.79 , and adding heating degree days changed the $\mathrm{R}^{2}$ by less than 0.01 . Based on this reasoning and on the fact that electricity is not the most important heating fuel in Italy, the temperature terms enter in our model in an additive fashion.

Before we specify equation (1) in detail, however, two matters must be resolved. The first is the choice of the time period $s$. There is an obvious mismatch between the frequency of the meter readings (every 15 minutes), and the times at which temperature is available in MERRA-2 (every 3 hours, namely at 0:00, 3:00, 6:00, 9:00, etc.). A number of alternatives are possible to handle this mismatch. One could, for example, use only the meter readings at the exact time when temperature is available. Doing so will result in 8 observations per household per day, but discards information about the loads at, say, 0:15, 0:30, etc.

Alternatively, one may aggregate (i.e., sum) the meter readings over three hours, matching 3-hour loads with the 3-hour temperatures. This will also produce 8 observations per household per day, does not discard any of the 15-minute loads, but may sacrifice information on the infra-hour variation in loads. Finally, one may impute temperature at the times when the temperature from the MERRA-2 dataset is not available in an effort to keep as many of the daily electricity meter readings as possible. This procedure should result in unbiased regression coefficients, but will "compress" the true variability of temperature and introduce heteroskedasticity, requiring appropriate correction of the standard errors (or, at a minimum, heteroskedasticity-robust standard errors; Little [27]). 
The second matter that must be addressed is the selection of the temperature "bins" $\left(\mathrm{T}_{\mathrm{j}}\right.$ in equation (1)). Narrow bins are desirable because impose minimal assumptions on the functional form of the relationship with electricity loads, but excessively narrow bins may contain too few observations and produce unstable regression results.

To strike a good balance between all of these considerations, we aggregate the 15 -minute meter readings to form total hourly usage and write regression (1) as:

$$
E_{i h t}=\alpha_{i h}+\theta_{i d}+\tau_{i m}+\gamma_{d m}+\lambda_{d h}+\beta_{1} \cdot \text { Dark }_{i h t}+\beta_{2} \cdot \text { Holiday }_{t}+\sum_{j=1}^{J} T_{j} \delta_{j}+\varepsilon_{i h t}
$$

where $i$ denotes the household, $d$ the day of the week (DOW), $m$ the month, $h$ the hour, and $t$ the exact date (day, month and year), and the $\mathrm{T}_{\mathrm{j}}$ are $2.5^{\circ} \mathrm{C}$ bins. Equation (2) includes i) householdby-hour fixed effects, ii) household-by-DOW fixed effects, iii) household-by-month fixed effects, iv) DOW-by-month fixed effects, and v) DOW-by-hour fixed effects.

With the household-by-hour fixed effects ( $\alpha_{\text {ih }}$ in equation (2)), we hope to capture hourly usage patterns that are specific to a household. For example, a household with early risers would be expected to incur the morning peak earlier than one where members do not get up as early; a household with children who come back from school would be expected to experience an early afternoon peak that would not be observed for households where everyone comes back from work in the evening, etc. The household-by-day of the week fixed effects $\left(\theta_{i d}\right)$ account for patterns typical of households with members who work or go to school versus households comprised exclusively of retired persons, while the household-by-month effects $\left(\tau_{i m}\right)$ helps capture personal holidays and/or school holidays, structural characteristics of the home that affect consumption on a seasonal basis, etc. ${ }^{13}$ Terms $\gamma_{d m}$ and $\lambda_{d h}$, namely the DOW-by-month

\footnotetext{
${ }^{13}$ Since we do not have any information about the dwelling type (e.g., single-family home, apartment in a building, etc.), vintage, construction materials, orientation and exposure to sunlight or wind, we are unable to explicitly account for building capacitance. The household-by-hour and household-by-month fixed effects may capture,
} 
and DOW-by-hour fixed effects, are assumed to be in common with all households. They are included to capture workweek and business schedules that are likely to alter the time spent at home and usage patterns of most people.

Taken together, the fixed effects seek to capture the effects of housing structure, family composition, work and school schedules, and seasonal variation in usage that is not necessarily due to temperature. There are a total of 16,506 fixed effects, and hence coefficients, to be estimated from a total of $3,310,524$ observations. ${ }^{14}$

Dark is the share of the hour before sunrise or after sunset, and is assumed to capture lighting-related electricity demand. The coefficient on this variable is identified off the variation in light across seasons (at 6:00am it is dark if in December, but bright and light in June) and on the same date within household and across locales (in the summer, for example, the sun rises earlier in Northern Italy than it does in Southern Italy). ${ }^{15}$ Holiday is a dummy for the major civic and religious holidays. The coefficient on the Holiday dummy captures the average additional effect of a holiday on hourly electricity consumption.

The terms $T_{j}$ in equation (2) are dummy variables denoting temperature bins, and are based on uniform bin widths of 2.5 degrees Celsius. The temperature intervals range from $-8^{\circ} \mathrm{C}$

among other things, capacitance. Wang and Bielicki [8] interpret some of the shifts in the lower and upper breakpoints over the day and in relation to the previous day's temperature as possibly due to building capacitance. ${ }^{14}$ Specifically, there are a total of 9072 household-by-hour fixed effects, 2646 household-by-day of the week fixed effects, 4356 household-by-month fixed effects, 168 day of the week-by-hour fixed effects, and 84 day-of-the-weekby-month fixed effects.

${ }^{15}$ Sunrise and sunset time vary significantly by date and town location. For instance, the family with ID=1 in our dataset experienced sunrise at times ranging from 5:41 - 8:07 and sunset from 16:47 to 21:19 in 2011. On the same day, the families living in Lecce (in Southeastern Italy) saw the sunset at 16:31 whereas the family in Sestu (Sardinia) saw the sunset 40 minutes later, at 17:10. The sunset and sunrise time are calculated using NOAA Sunrise/Sunset and Solar Position Calculators, which is based on equations from Astronomical Algorithms by Jean Meeus. The sunrise and sunset results are theoretically accurate to within a minute for locations between $+/-72^{\circ}$ latitude, and within 10 minutes outside of those latitudes. Since Italy has a latitude ranging from 36.7 to $47^{\circ}$, NOAA's solar calculator is well suited. We use the coordinates of each town to calculate the site- and date-specific sunrise and sunset times, and compare each hour of the day with the sunrise and sunset time of this day at each location to generate the Dark variable. 
to $38^{\circ} \mathrm{C}$ by $2.5^{\circ} \mathrm{C}$. To place the temperature in the appropriate bins, we linearly interpolated the 3-hour temperatures from MERRA-2 to fill in the missing hourly values (e.g., those at 1:00, 2:00, 4:00, 5:00, etc.).

\section{Results}

We report selected coefficients from running OLS on equation (2) in table 6. All standard errors are clustered at the household-day level, and are thus heteroskedasticity-robust. ${ }^{16}$ Briefly, we find evidence that temperature does influence electricity consumption above and beyond other household, dwelling, time and seasonal effects. The R square of the regression, however, only increases from 0.3978 to 0.3988 when the temperature terms are added.

The coefficients on the temperature in dummies are plotted in figure 4. They exhibit a "hockey-stick" or "J" shape, with a relatively flat left side (at low temperatures), a relatively flat bottom between $16^{\circ}$ and $24.4^{\circ} \mathrm{C}$, and a very steep increase as temperature rises above $24.4^{\circ} \mathrm{C}$. Based on the coefficients in table 6 , at $32.5^{\circ} \mathrm{C}$ electricity consumption is, all else the same, some $41 \%$ higher than the baseline (which is the omitted category in our regression, namely when the temperature is below $-3.7^{\circ} \mathrm{C}$ ).

\footnotetext{
${ }^{16}$ We remind the reader that equation (2) is based on hourly loads (i.e., the sum of four 15 -minute meter readings) and hourly temperatures. Appendix A, table A.1, reports results from running regression (2) on i) only the hours at each temperatures from the MERRA-2 dataset are available (panel (A)), ii) three-hour loads and the 3-hour temperatures (panels (B) and (C)), and the approach we finally settled on (described in Section 2.2; panel (D)). Table A.1 shows that the coefficients on the temperature bin dummies are virtually the same across approaches (keeping in mind that the coefficients in panel (B) and (C) must be divided by three to compare them to those in panels (A) and (D)), but those in panel (D) tend to have the smallest standard errors. In Appendix B we experiment with different temperature bin widths and plot the resulting coefficients. The first graph shows that using one-degree bins may result in a graph with some "jagged edge" segments. We attribute this "instability" to the few data points that fall in certain bins. Increasing the bin width produces more stable results, due to the larger number of data points in each bin, and the general shape of the relationship with electricity usage is unaffected.
} 
Panel B of Figure 4 displays the load v. temperature relationship by income group. The general shape of the relationship is the same as in panel A. It is noteworthy that load appears to increase at temperatures above $24.4^{\circ} \mathrm{C}$ just as sharply across all income groups. (We attribute the drop for the highest temperature bin for low-income households to imprecision due to the small number of observations that fall in that bin.) As shown in panel $\mathrm{C}$ of Figure 4 at the highest temperatures the increase in load is sharper for households with more "white goods." Appendix $\mathrm{C}$ reports the coefficients on the temperature bin dummies from fitting equation (2) to the subsamples from Northern Italy, Central Italy, the South and the two major islands, namely Sicily and Sardinia. The pattern for Northern and Southern Italy is similar to that for the full sample. That for Sicily and Sardinia, which generally enjoy milder weather in the winter and are apparently less likely to experience the extremely hot days sometimes observed in the North, is more difficult to interpret, and may be in part due to the smaller number of observations. There are over a million observations from Central Italy in our sample, so we trust that the much more limited responsiveness to temperature is genuine and not an artifact of a smaller or more unbalanced sample.

Figure 5 shows that the effect of temperature is small compared to other household, dwelling, time and seasonal factors (the fixed effects of equation (2)) and even to that of dark v. light times of the day. The share of usage attributable to lighting clearly increases during winter, while that of temperature alone is most pronounced in the summer months (and in the coldest winter months). We arrive at this conclusion after using the estimated coefficients to predict, for each household, hour and day of the study, (i) the fixed effects in the right-hand side of equation (2), (ii) the predicted temperature component (i.e., $\sum_{j} T_{j} \hat{\delta}_{j}$ ), (iii) the predicted light v. darkness component (i.e., Dark $\cdot \hat{\beta}_{1}$ ), and iv) the predicted holiday component (i.e., Holiday $\cdot \hat{\beta}_{2}$ ). The 
total predicted load for that household, hour and day of the year is thus the sum of (i), (ii), (iii) and (iv). We then take the average of the total hourly loads and of their separate components over each month. Figure 5 displays such averages for (i), (ii) and (iii), ignoring component (iv), which proved to be negligible.

In figure 6 we plot the average of each component of electricity consumption across households for each temperature bin. ${ }^{17}$ This graph shows that the fixed effects component does increase somewhat with temperature, presumably as a result of seasonal behaviors that tend to be correlated with temperature and that we do not perfectly separate from temperature, but the effect of temperature alone rises at a much sharper rate. By contrast, the portion of the load due to lighting declines with temperature, as there are more hours of daylight in the summer, when the temperatures are higher.

Figure 7 depicts the share of total electricity consumption attributable to the temperatures of that day for each day of the 2011 year (blue line). This share is computed as the load attributable to temperature, i.e., the term $\sum_{j=1}^{J} T_{j} \hat{\delta}_{j}$ in equation (2), divided by the full predicted load $\left(\hat{E}_{i h t}\right)$. The share is generally small (2.5\% on average for the entire summer) but as high as $9 \%$ on certain days in the summer (22-23 August).

In addition, figure 7 graphically displays the results from the following exercise. Suppose our sample had experienced, in 2011, the same temperatures, hour by hour, as in the corresponding days of 2003 - a year with an extremely hot summer (see Figures D.1 and D.2 in Appendix D). The orange line in Figure 8 represents the share of total consumption associated with the 2003 temperatures, which is clearly much higher than that for the 2011 summer. The

\footnotetext{
${ }^{17}$ We followed a procedure similar to that used to produce figure 6, except that this time we average the hourly consumption levels predicted by our model over the temperatures in each bin (rather than over each month).
} 
share during the summer of 2003 would have been on average $4 \%$, reaching $11-12 \%$ in at least four days in August 2003 and 9\% or higher on 10 days of the summer. Over the entire summer (June 21-September 21), our households would have used $12.6 \%$ more electricity in 2003 than they are predicted to have used in 2011. Over the entire year, our households would have used 5\% more electricity in 2003 than they are predicted to have used in 2011.

We are also interested in a more gradual, less extreme, type of temperature increase. For example, we predict consumption if the temperature had been higher by $1^{\circ} \mathrm{C}$, hour by hour, than the value observed in 2011. This time the summer increase is completely offset by the decline in the other seasons, and total electricity usage is predicted to be lower than the predicted value for 2011. The difference is however only one-tenth of one percent.

\section{Conclusions}

We have used a unique dataset documenting hourly electricity loads from a geographically representative sample of families in Italy to study the relationship between consumption and temperature. Unlike earlier analyses based on total daily load at the national level (and hence aggregated by geography, time of the day, and over industrial, commercial and residential users), we have exploited the variation in temperature across locales and within the day and disentangled the effect of dark v. light time of day off the variation across seasons and the different sunrise and sunset hours across the northern and southern parts of the country within the same day. We have used a rich set of fixed effects to control for behaviors that vary across households, within the day, and over the year. The purpose of these fixed effects is to seek to disentangle the effect of temperature from that of lighting and of behaviors and habits that depend on other, seasonal factors potentially correlated with temperature, but different from 
temperature. This is a significant advancement in the state of the knowledge about temperatures and electricity demand, as separating empirically the potentially different sensitivities to increases in the average global temperature across residential customers is an analytically important step towards understanding the integration of cooling.

The results are striking. Instead of a deep and asymmetric V curve (as in Damm et al. [11], and Wenz et al. [12]), the effect of temperature appears to be rather flat at low and mild temperatures. At about $24.4^{\circ} \mathrm{C}$ and higher temperatures, however, electricity use rises sharply with temperature. The sensitivity of residential electricity load profiles is greater at higher temperatures, echoing findings at other locations and with more aggregate data (e.g., Wang and Bielicki [8]). This finding is robust across the different market zones in Italy, income quintiles in our samples, and possession of white goods, even though the gradient of the curve may be steeper for households that own more numerous appliances.

While on very hot days temperature can account for as much as $9-12 \%$ of total electricity usage (depending on the weather extremes we considered), very hot days account for a small share of the total number of days, and for this reason the share of electricity usage attributable to temperature is on average only $3 \%$. Such low share is consistent with the fact that in the largest majority of homes in Italy space heating is provided by gas boilers, and electric heating systems are rare.

We conduct two exercises to evaluate the possible impact of future climate at the current technologies and habit. The first assumes that households had experienced in 2011 , locale by locale and hour by hour, the same temperatures as in 2003, when the summer was extremely hot. This would have raised summer consumption by $12 \%$ and annual consumption by $5 \%$. Temperatures like the ones experienced in 2003 are expected to become the norm after 2060, just 
as Europe is experiencing hotter and hotter summers even in Scandinavia and normally colder countries (Rubin [28]). The second exercise assumes instead a uniform increase in temperature by $1^{\circ} \mathrm{C}$, showing that the change in total annual consumption would have been quite small. 


\section{References}

[1] Intergovernmental Panel on Climate Change (2014), "Climate Change 2014. Synthesis Report. Summary for Policymakers," available at https://www.ipcc.ch/pdf/assessmentreport/ar5/syr/AR5_SYR_FINAL_SPM.pdf (last accessed 7 August 2018).

[2] Tobin, I. et al. (2018), "Vulnerability and Resilience of European Power Generation to $1.5^{\circ}$ C, $2^{\circ} \mathrm{C}$ and $3^{\circ} \mathrm{C}$ Warming," Environmental Research Letters, 13, 044024.

[3] International Energy Agency (2018), "The future of cooling." Available at https://www.iea.org/futureofcooling/ (last accessed 22 January 2019).

[4] Brown, M., M. Cox, B. Staver and P. Baer (2014), "Climate Change and Energy Demand in Buildings," ACEEE Summer Study on Energy Efficiency in Buildings, available at https://aceee.org/files/proceedings/2014/data/papers/3-736.pdf, last accessed 19 July 2018.

[5] Auffhammer, M., P. Baylis, and C. H. Hausman (2017), "Climate Change is Projected to Have Severe Impacts on the Frequency and Intensity of Peak Electricity Demand Across the United States," Proceedings of the National Academy of Sciences, 114(8), 1886-1891.

[6] Franco, G., and A. H. Sanstad (2008), "Climate Change and Electricity Demand in California," Climatic Change, 87(Suppl. 1), S139-S151.

[7] Khanna, S. (2012), "Impact of Climate Change on Residential Electricity Consumption: Evidence from Weather Fluctuations across Building Climate Zones in California" unpublished thesis, University of Maryland, College Park, May.

[8] Wang, Y., and J. Bielicki, (2018), "Acclimation and the Response of Hourly Electricity Loads to Meteorological Variables," Energy, 142, 473-485.

[9] Ahmed, T., D. H.Vu, K. M. Muttaqi, and A. P. Agalgaonkar (2018), "Load Forecasting Under Changing Climatic Conditions for the City of Sydney, Australia," Energy, 142, 911-919.

[10] Jiang, D., W. Xiao, J. Wang, H. Wang, Y. Zhao, B. Li, and P. Zhou (2018), "Evaluation of the Effects of One Cold Wave on Heating Energy Consumption in Different Regions of Northern China," Energy, 142, 331-338.

[11] Damm, A., J. Köberl, F. Prettenhaler, N. Rogler, and C. Töglhofer (2017), "Impacts of a $+2^{\circ}$ C global warming on electricity demand in Europe," Climate Services, 7, 12-30.

[12] Wenz, L., A. Levermann, and M. Auffhammer (2017), "North-South Polarization of European Electricity Consumption under Future Warming," Proceedings of the National Science Academy, 114(38), E7910-E7918. 
[13] Dirks, J. A., W. J. Gorrissen, J. H. Hathaway, D. C. Skorski, M. J. Scott, T. C. Pulsipher, M. Huang, Y. Liu, and J. S. Rice (2015), "Impacts of climate change on energy consumption and peak demand in buildings: A detailed regional approach," Energy, 79, 20-32.

[14] Afshari, A., and L. A., Friedrich (2017), "Inverse modeling of the urban energy system using hourly electricity demand and weather measurements, Part 1: Black-box model," Energy and Buildings, 157, 126-138.

[15] Birt, B. J., G.R. Newsham, I. Beausoleil-Morrison, M. M. Armstrong, N. Saldanha, and I. H. Rowlands (2012), "Disaggregating categories of electrical energy end-use from whole-house hourly data," Energy and Buildings, 50, 93-102.

[16] Mirasgedis, S., Y. Sarafidis, E. Georgopoulou, D. P. Lalas, M. Moschovits, F. Karagiannis, and D. Papakonstantinou (2006), "Models for mid-term electricity demand forecasting incorporating weather influences," Energy, 31(2-3), 208-227.

[17] Summerfield, A.J., T. Oreszcyn, I.G. Hamilton, D. Shipworth, G.M. Huebner, R.J. Lowe, and P. Ruyssevelt (2015), "Empirical Variation in 24-h profiles of delivered power for a sample of UK dwellings: Implications for evaluating energy savings," Energy and Buildings, 88, 193-202.

[18] ARERA (2012), "Relazione Annuale Sullo Stato dei Servizi e sull'Attività Svolta,” 31 March 2012, page 52.

[19] Jylhä, K., J. Jokisalo, K., Ruosteenoja, K. Pilli-Sihvola, T. Kalamees, T. Seitola, and A. Drebs (2015), "Energy demand for the heating and cooling of residential houses in Finland in a changing climate," Energy and Buildings, 99, 104-116.

[20] Fouillet, A., G. Rey, F. Laurent, G. Pavillon, S. Bellec, C. Guihenneuc-Jouyaux, E. Jougla, and D. Hemon (2006), "Excess Mortality Related to the August 2003 Heat Wave in France," 80(1), International Archives of Occupational and Environmental Health, 80(1), $16-24$.

[21] ARERA (2018), “Capacity-based Network Tariffs for Italian Electricity Households," presentation by Luca Lo Schiavo and Emanuele Regalini at the Network Tariffs Workshop, Brussels, October, available at https://www.ceer.eu/documents/104400/-/lc2310057-9124-4708-8f56-6a587f76f569

[22] McFadden, D., C. Puig, and D. Kirshner (1977), “'Determinants of the Long-Run Demand for Electricity." Proceedings of the American Statistical Association, 109-19. 17.

[23] Reiss, P. C. and M. W. White (2005), "Household Electricity Demand, Revisited," Review of Economic Studies, 72, 851-883.

[24] Alberini, A., W. Gans, and D. Velez-Lopez (2011), "Residential Consumption of Gas and Electricity in the U.S.: The Role of Prices and Income," Energy Economics, 33(5), 870881. 
[25] Alberini, A., C. Towe and W. Gans (2016), "Energy Efficiency Incentives: Do They Work for Heating and Cooling Equipment? Evidence from Maryland Homeowners," The Energy Journal, 37(1), 259-290.

[26] Alberini, A., O. Khymych, and M. Ščasný (2019), "Response to Extreme Price Changes: Evidence from Ukraine," The Energy Journal, 40(1), 189-212.

[27] Little, R. J. A. (1992), “Regression with Missing X's: A Review,” Journal of the American Statistical Association, 87(420). 1227-1237.

[28] Rubin, A. J. (2018), “A Miserably Hot Europe is Fast Becoming the Norm," The New York Times, 5 August. 
Table 1. Geographical distribution of the sample and comparison with the population of Italy in 2011.

\begin{tabular}{|c|c|c|c|c|}
\hline Region & $\begin{array}{c}\text { number of } \\
\text { households } \\
\text { in the } \\
\text { sample }\end{array}$ & $\begin{array}{l}\text { percent } \\
\text { of the } \\
\text { sample }\end{array}$ & $\begin{array}{c}\text { Census 2011*: } \\
\text { Number of } \\
\text { persons }\end{array}$ & $\begin{array}{c}\text { Census } \\
2011^{*}: \\
\text { Percent of } \\
\text { the total } \\
\text { population }\end{array}$ \\
\hline Abruzzo & 7 & $1.77 \%$ & $1,307,309$ & $2.23 \%$ \\
\hline Basilicata & 8 & $2.02 \%$ & 578,036 & $0.99 \%$ \\
\hline Calabria & 11 & $2.78 \%$ & $1,959,050$ & $3.35 \%$ \\
\hline Campania & 35 & $8.84 \%$ & $5,766,810$ & $9.85 \%$ \\
\hline Emilia Romagna & 41 & $10.35 \%$ & $4,342,135$ & $7.42 \%$ \\
\hline Friuli Venezia Giulia & 3 & $0.76 \%$ & $1,218,886$ & $2.08 \%$ \\
\hline Lazio & 19 & $4.80 \%$ & $5,502,866$ & $9.40 \%$ \\
\hline Liguria & 6 & $1.52 \%$ & $1,570,694$ & $2.68 \%$ \\
\hline Lombardia & 63 & $15.91 \%$ & $9,704,151$ & $16.57 \%$ \\
\hline Marche & 12 & $3.03 \%$ & $1,541,319$ & $2.63 \%$ \\
\hline Molise & 4 & $1.01 \%$ & 313,660 & $0.54 \%$ \\
\hline Piemonte & 25 & $6.31 \%$ & $4,363,916$ & $7.45 \%$ \\
\hline Puglia & 26 & $6.57 \%$ & $4,052,566$ & $6.92 \%$ \\
\hline Sardegna & 6 & $1.52 \%$ & $1,639,362$ & $2.80 \%$ \\
\hline Sicilia & 21 & $5.30 \%$ & $5,002,904$ & $8.54 \%$ \\
\hline Toscana & 41 & $10.35 \%$ & $3,672,202$ & $6.27 \%$ \\
\hline Umbria & 6 & $1.52 \%$ & $1,029,475$ & $1.76 \%$ \\
\hline Val d'Aosta & 0 & $0.00 \%$ & 126,806 & $0.22 \%$ \\
\hline Veneto & 44 & $11.11 \%$ & $4,857,210$ & $8.30 \%$ \\
\hline missing & 18 & $4.55 \%$ & & \\
\hline Total & 396 & $100.00 \%$ & $58,549,357$ & $100.00 \%$ \\
\hline
\end{tabular}

* Source: Census data, as reported in

http://www.citypopulation.de/Italy-Cities.html 
Table 2. Descriptive statistics: Homes and households.

\begin{tabular}{lrrrr}
\hline \hline \multicolumn{1}{c}{ variable } & mean & standard & & \\
deviation & min & max \\
\hline \hline size of the home in square meters & 103.52 & 36.4 & 30 & 200 \\
number of household members & 2.68 & 1.21 & 1 & 6 \\
number of total electric appliances & 17.47 & 5.34 & 4 & 36 \\
has one electric water heater (share of the sample) & 0.1349 & 0.3416 & 0 & 1 \\
has two electric water heaters (share of the sample) & 0.0159 & 0.1251 & 0 & 1 \\
\hline \hline
\end{tabular}

Table 3. Descriptive statistics: White goods owned by the household.

\begin{tabular}{ll}
\hline \hline Number of white goods & Percent of the households \\
\hline \hline 1 & 1.01 \\
2 & 29.04 \\
3 & 36.11 \\
4 & 18.69 \\
5 & 7.83 \\
6 & 2.53 \\
7 & 0.25 \\
missing & 4.55 \\
\hline \hline
\end{tabular}

Table 4. Descriptive Statistics: Income

\begin{tabular}{ll}
\hline \hline Income category & Percent of the households \\
\hline \hline Very low & 4.04 \\
Low & 15.91 \\
Mid-income & 41.17 \\
High & 17.93 \\
Very high & 15.40 \\
missing & 4.55 \\
\hline \hline
\end{tabular}


Table 5. Descriptive Statistics: Temperature and electricity usage.

\begin{tabular}{lrrrr}
\hline \hline \multicolumn{1}{c}{ variable } & \multicolumn{2}{c}{ standard } & \\
& mean & deviation & \multicolumn{1}{c}{$\min$} & \multicolumn{1}{c}{$\max$} \\
\hline \hline temperature in ${ }^{\circ} \mathrm{C}$ & 22.06 & 3.88 & 4.47 & 37.47 \\
hourly electricity consumption in $\mathrm{kWh}$ & 0.2993 & 0.3029 & 0 & 3.938 \\
\hline \hline
\end{tabular}

Table 6. Summary of regression results: Selected coefficients from regression equation (2).

\begin{tabular}{lrrr}
\hline \hline Regressor & Coefficient & Std. error & T stat. \\
\hline \hline Holiday (dummy) & 0.0086 & 0.0051 & 1.70 \\
\hline Dark (share of the hour in the dark) & 0.0777 & 0.0038 & 20.34 \\
\hline Temp.: -3.7 to $-1.2^{\circ} \mathrm{C}$ (dummy) & 0.0314 & 0.0095 & 3.32 \\
\hline Temp.: -1.2 to $1.4^{\circ} \mathrm{C}$ (dummy) & 0.0250 & 0.0034 & 7.30 \\
\hline Temp.: 1.4 to $4^{\circ} \mathrm{C}$ (dummy) & 0.0232 & 0.0053 & 4.39 \\
\hline Temp.: 4 to $6.5^{\circ} \mathrm{C}$ (dummy) & 0.0220 & 0.0052 & 4.27 \\
\hline Temp.: 6.5 to $9.1^{\circ} \mathrm{C}$ (dummy) & 0.0164 & 0.0057 & 2.85 \\
\hline Temp.: 9.1 to $11.6^{\circ} \mathrm{C}$ (dummy) & 0.0113 & 0.0058 & 1.97 \\
\hline Temp.: 11.6 to $14.2^{\circ} \mathrm{C}$ (dummy) & 0.0055 & 0.0061 & 0.91 \\
\hline Temp.: 14.2 to $16.7^{\circ} \mathrm{C}$ (dummy) & 0.0016 & 0.0063 & 0.26 \\
\hline Temp.: 16.7 to $19.3^{\circ} \mathrm{C}$ (dummy) & -0.0032 & 0.0065 & -0.50 \\
\hline Temp.: 19.3 to $21.8^{\circ} \mathrm{C}$ (dummy) & -0.0018 & 0.0066 & -0.27 \\
\hline Temp.: 21.8 to $24.4^{\circ} \mathrm{C}$ (dummy) & -0.0030 & 0.0070 & -0.44 \\
\hline Temp.: 24.4 to $26.9^{\circ} \mathrm{C}$ (dummy) & 0.0112 & 0.0077 & 1.46 \\
\hline Temp.: 26.9 to $29.5^{\circ} \mathrm{C}$ (dummy) & 0.0439 & 0.0119 & 3.70 \\
\hline Temp.: 29.5 to $32^{\circ} \mathrm{C}$ (dummy) & 0.0845 & 0.0169 & 4.99 \\
\hline Temp.: 32 to $34.6^{\circ} \mathrm{C}$ (dummy) & 0.1164 & 0.0250 & 4.65 \\
\hline Temp.: 34.6 to $37.8^{\circ} \mathrm{C}$ (dummy) & 0.1741 & 0.0417 & 4.17 \\
\hline constant & 0.2510 & 0.0063 & 40.07 \\
\hline \hline Note: The regression also include & & 0.646
\end{tabular}

Note: The regression also include household-by-hour, household-by-day of the week, household-by-month, day of the week-by-month and day of the week-by-hour fixed effects. Standard errors are clustered at the household-day level. 
Figure 1. Distribution of hourly temperature in 2011.

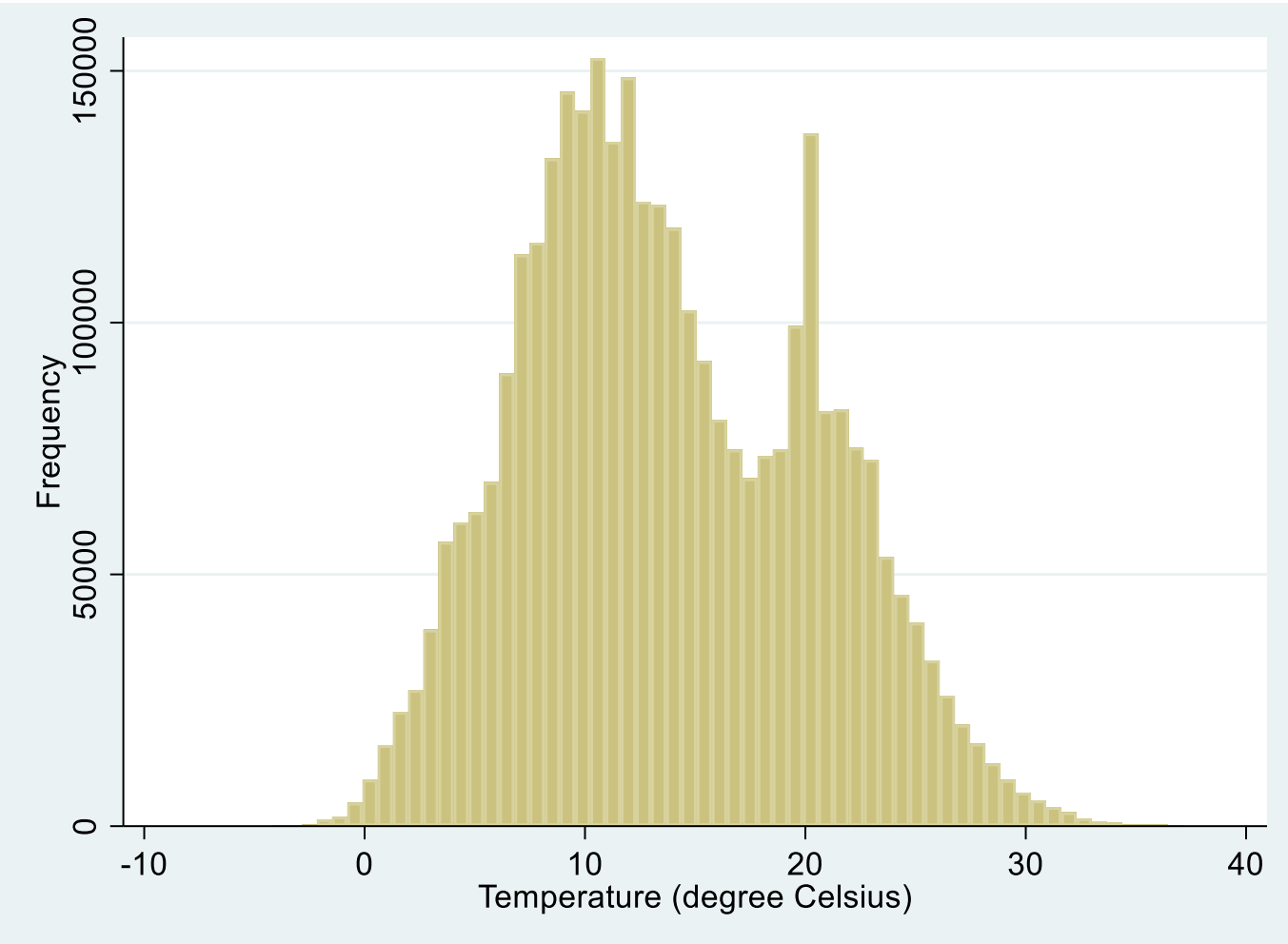


Figure 2. Hourly electricity consumption throughout the day: Weekday v. Weekend. (Average hourly load over the entire year 2011.)

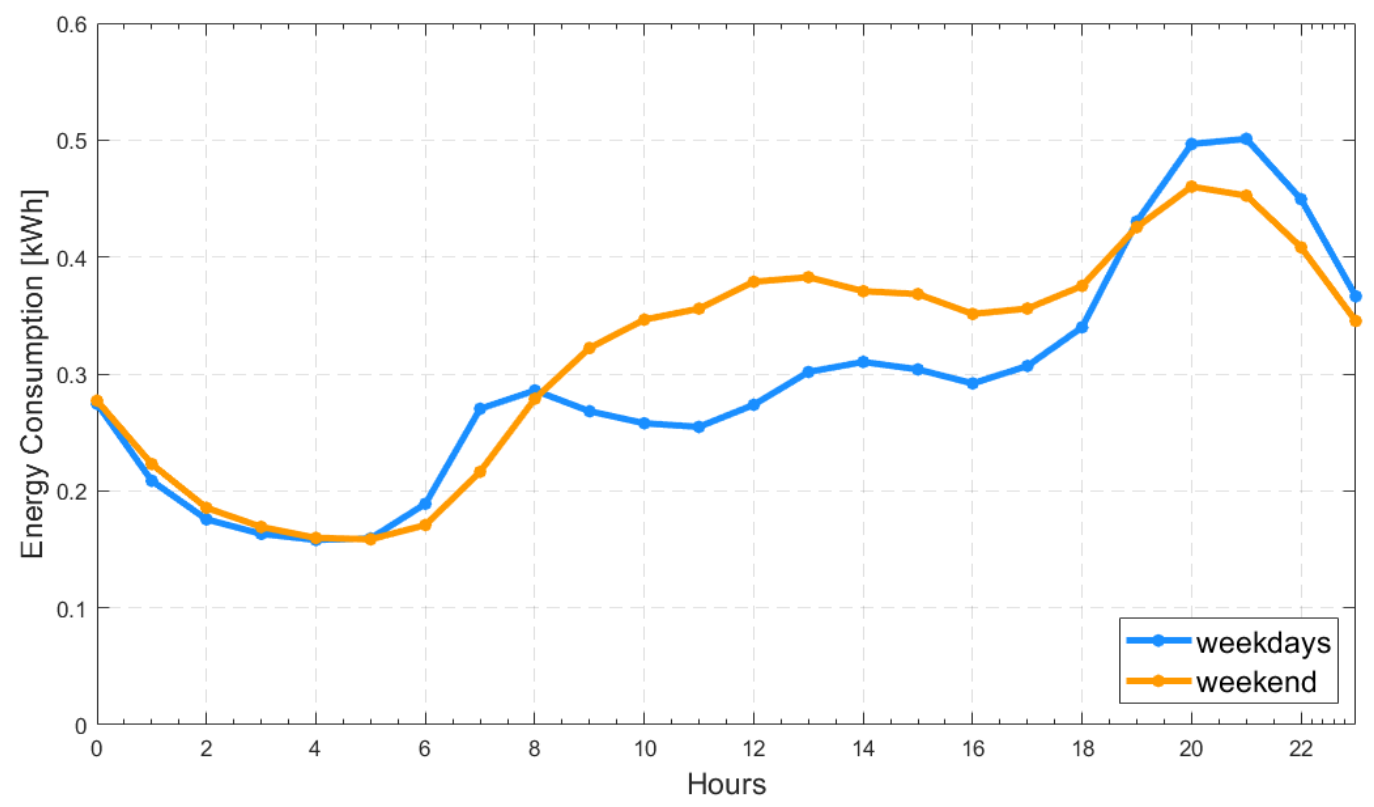

Figure 3. Average daily usage by temperature.

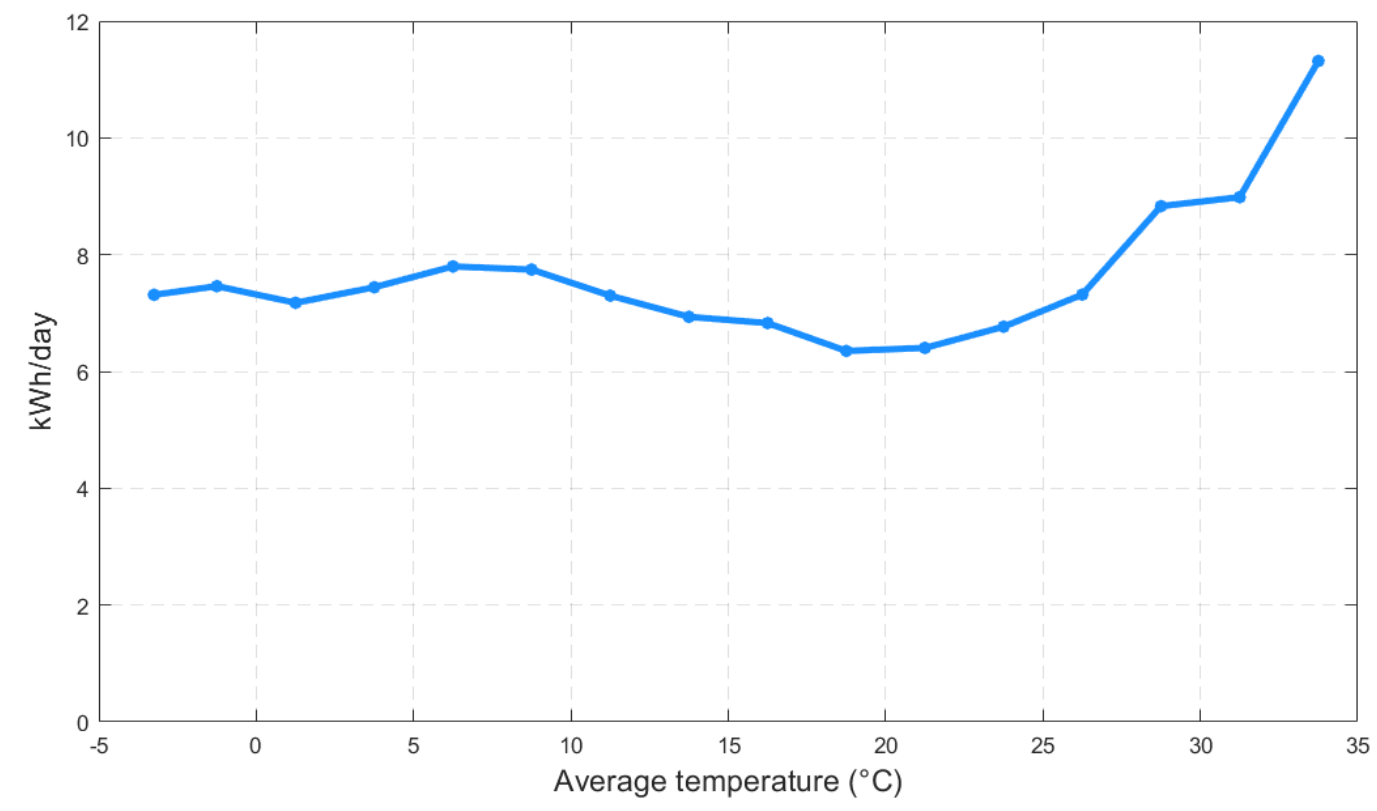

Figure 4. Effect of temperature on hourly electricity usage. 
A. Full sample.

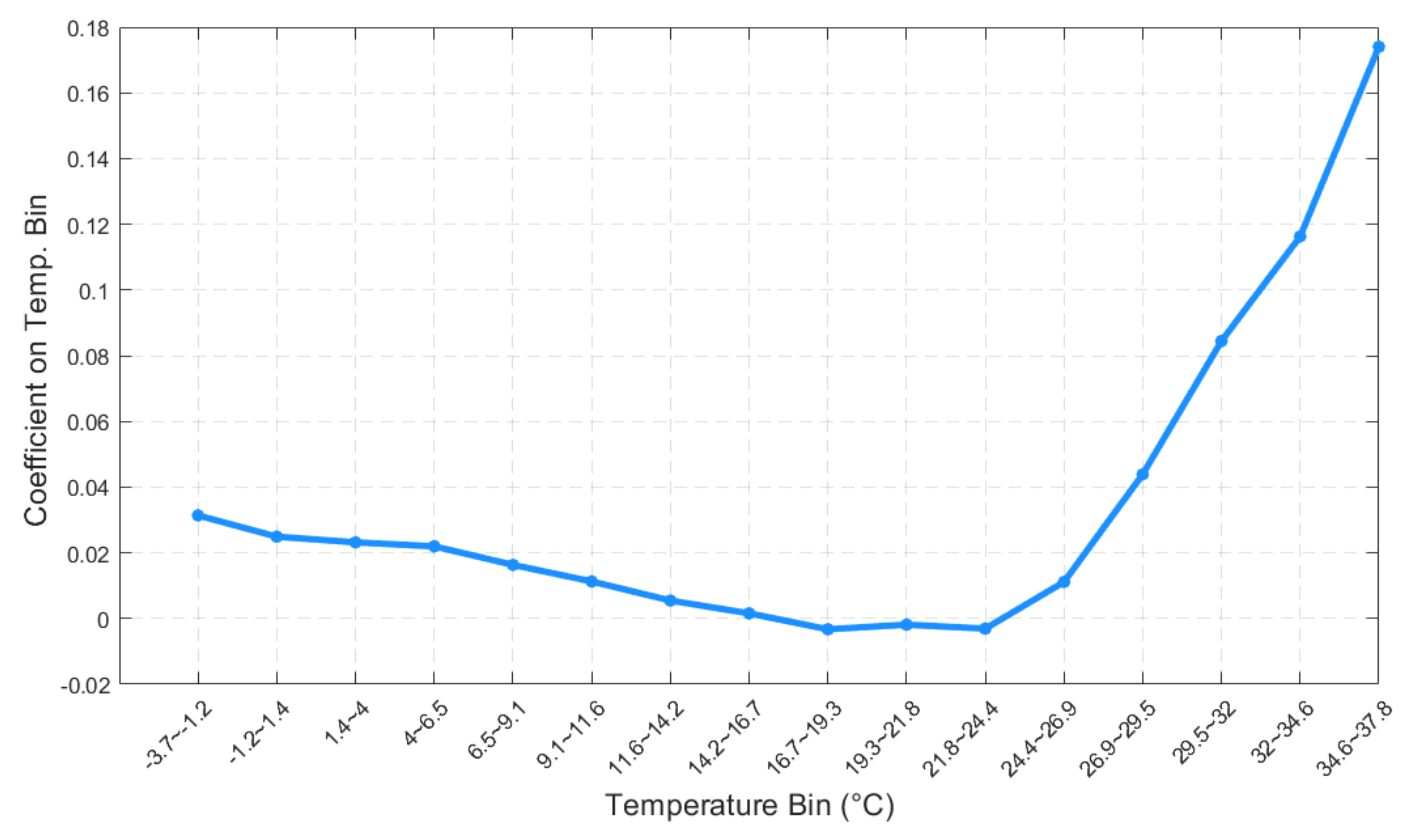

B. By income category.

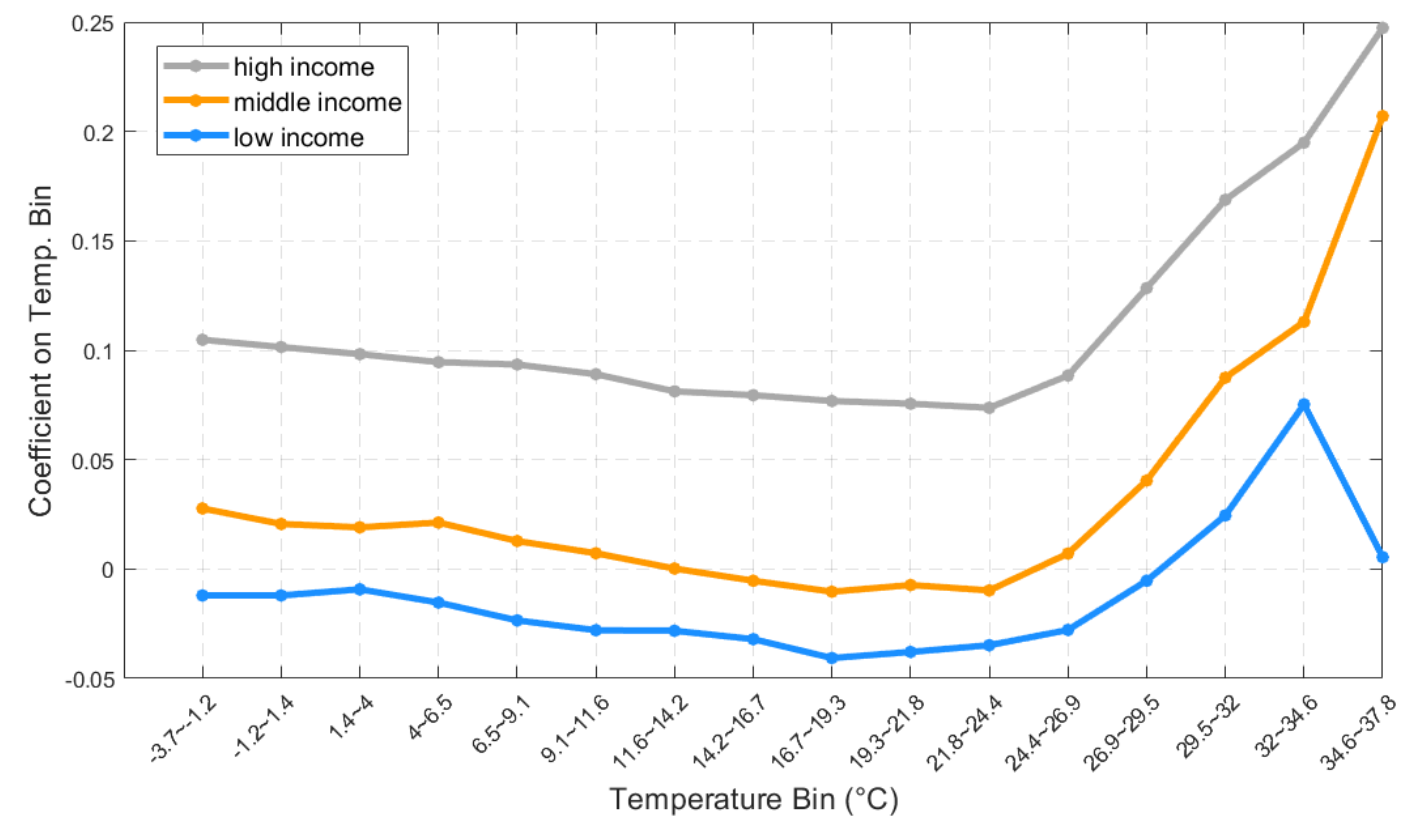

Note: The label "low income" refers to both low income and very low income households. "High income" covers households classified as high income as well as those classified as very high income. 
C. Effect of temperature on hourly electricity usage: Role of number of white goods owned.

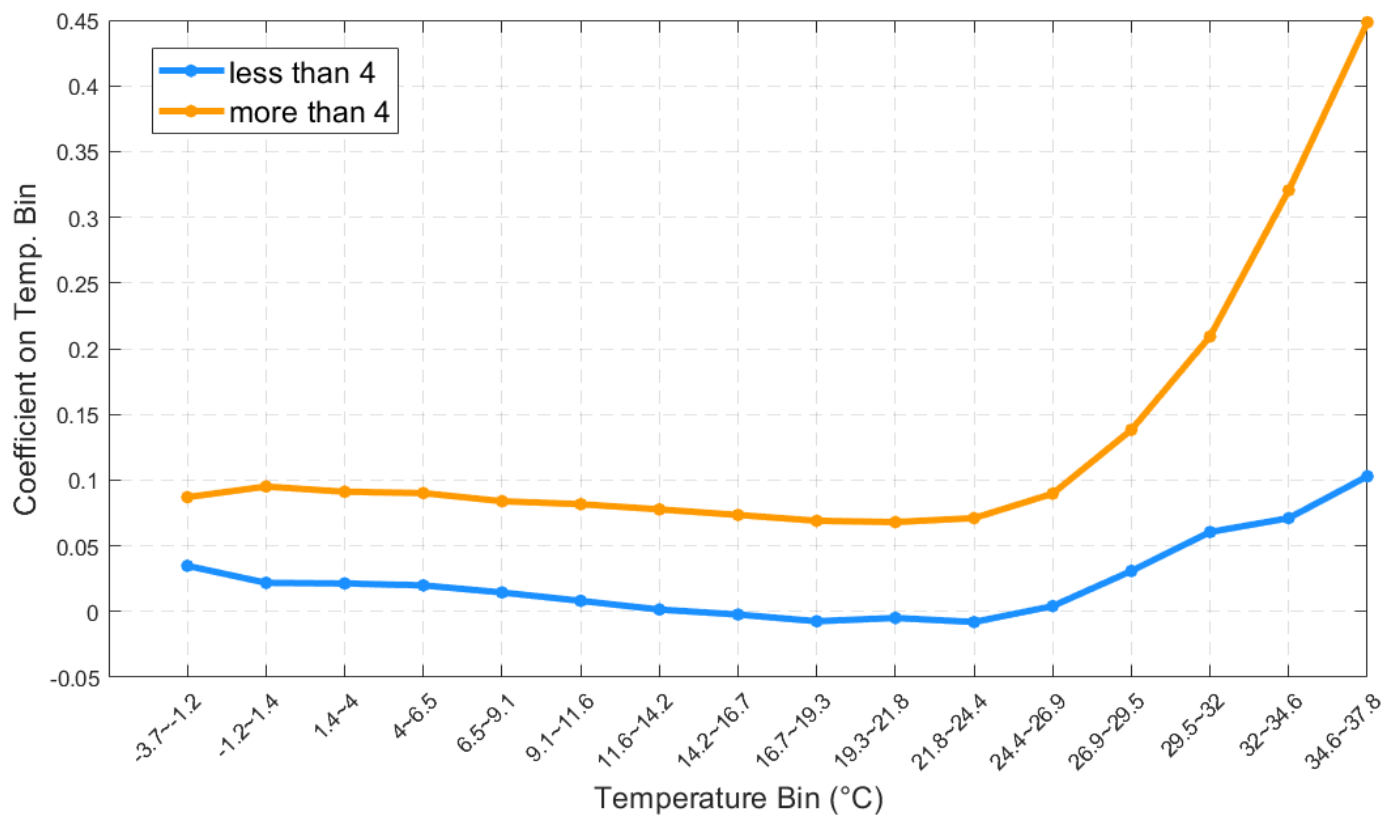


Figure 5. Contribution of temperature and darkness/light v. fixed effects to hourly electricity usage.

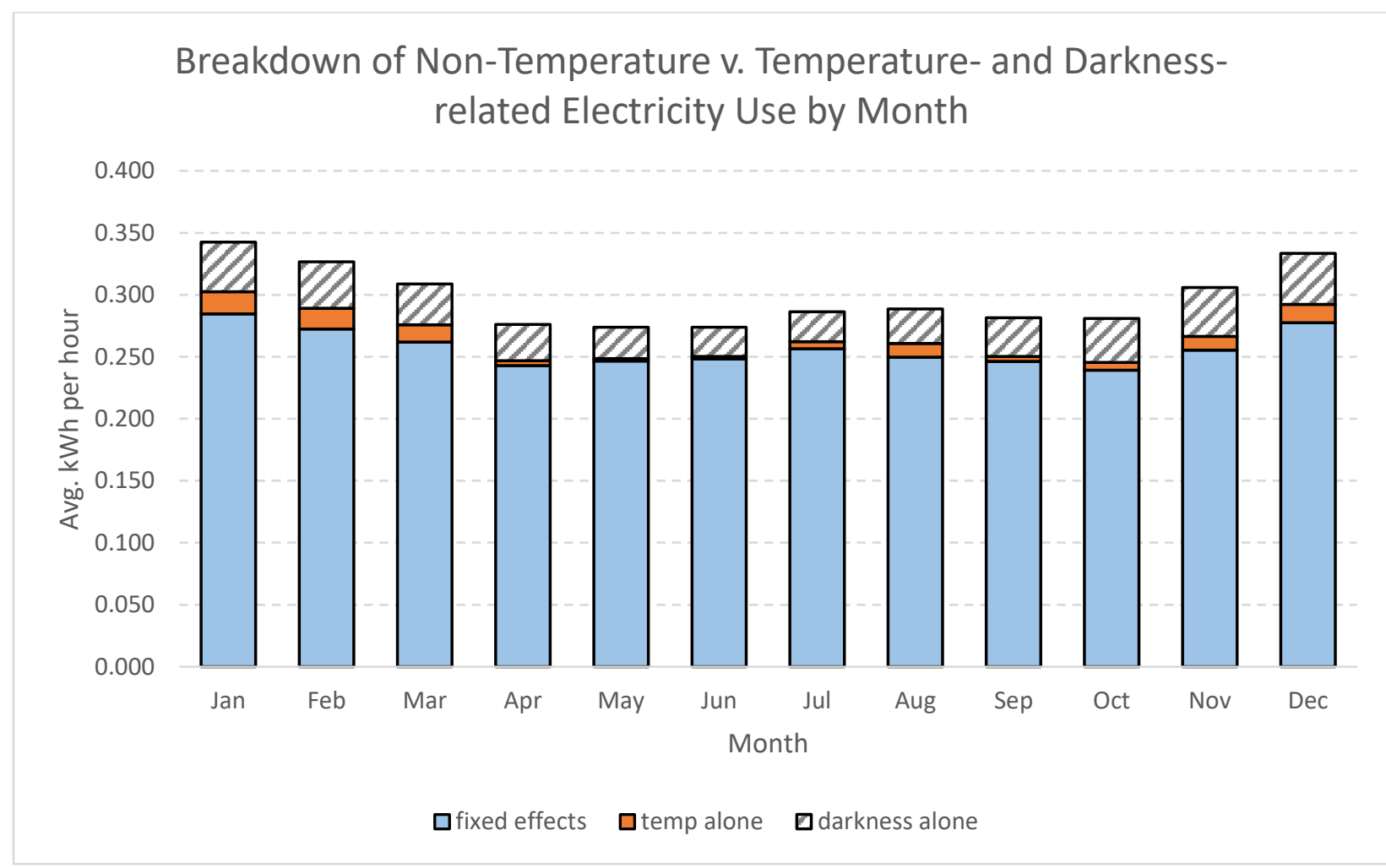

Note: This chart was construct as follows. Using the regression results (see table 6) we predict, for each household, hour and day of the study, (i) the fixed effects in the righthand side of equation (2), (ii) the predicted temperature component (i.e., $\sum_{j} T_{j} \hat{\delta}_{j}$ ), (iii) the predicted light v. darkness component (i.e., Dark $\cdot \hat{\beta}_{1}$ ), and iv) the predicted holiday component (i.e., Holiday $\cdot \hat{\beta}_{2}$ ). The total predicted load for that household, hour and day of the year is thus the sum of (i), (ii), (iii) and (iv). We then take the average of the total hourly loads or their separate components over each month of the year. The charts displays such averages for (i), (ii) and (iii), ignoring component (iv), which proved to be negligible. 
Figure 6. Hourly consumption by temperature bin. Based on the full year of data.

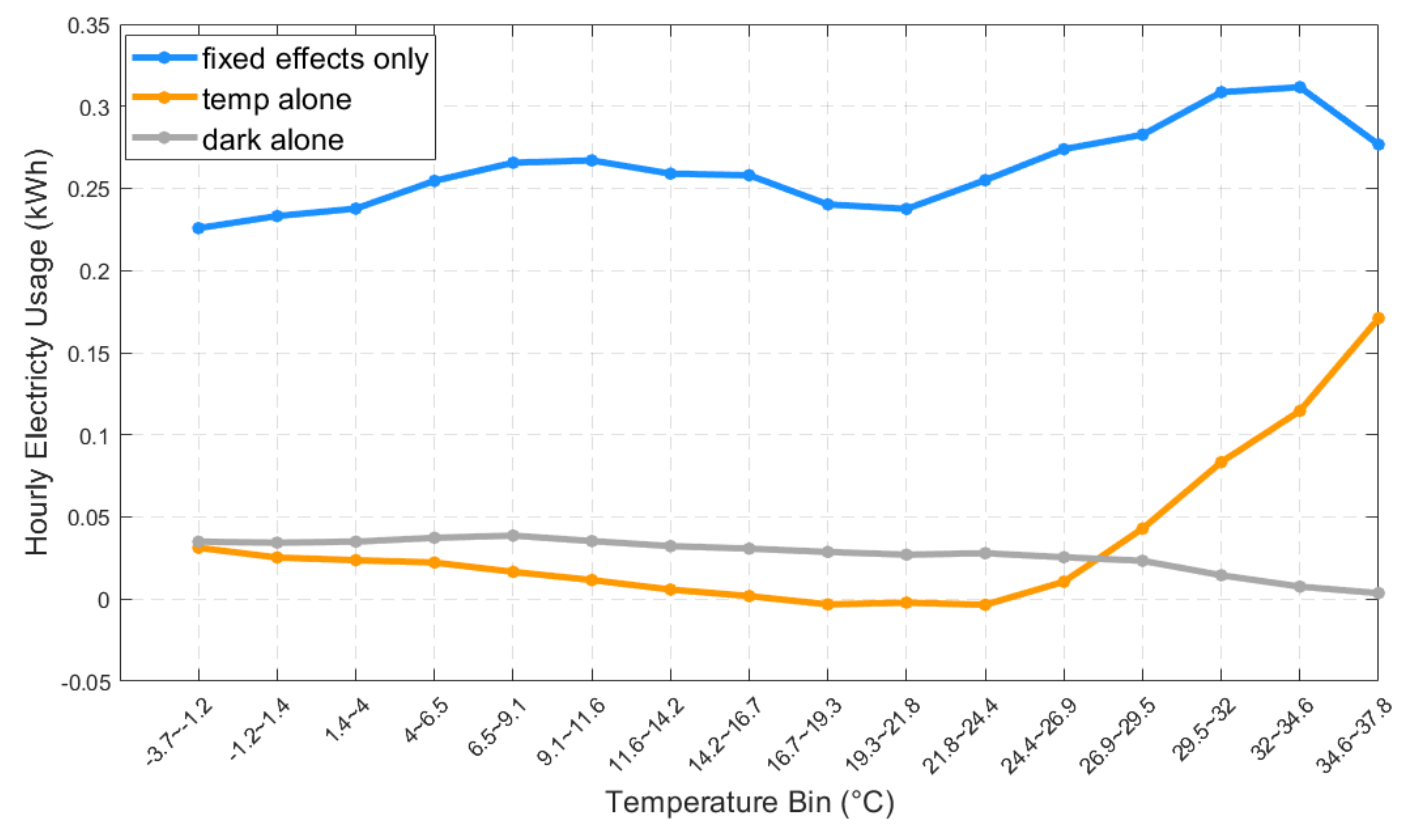

Note: This chart was construct as follows. Using the regression results (see table 6) we predict, for each household, hour and day of the study, (i) the fixed effects in the right-hand side of equation (2), (ii) the predicted temperature component (i.e., $\sum_{j} T_{j} \hat{\delta}_{j}$ ), (iii) the predicted light v. darkness component (i.e., $\operatorname{Dark} \cdot \hat{\beta}_{1}$ ), and iv) the predicted holiday component (i.e., Holiday . $\hat{\beta}_{2}$ ). The total predicted load for that household, hour and day of the year is thus the sum of (i), (ii), (iii) and (iv). We then take the average of the total hourly loads or their separate components over each temperature bin. 
Figure 7. Share of total electricity consumption accounted for by temperature: 2003 v. 2011.

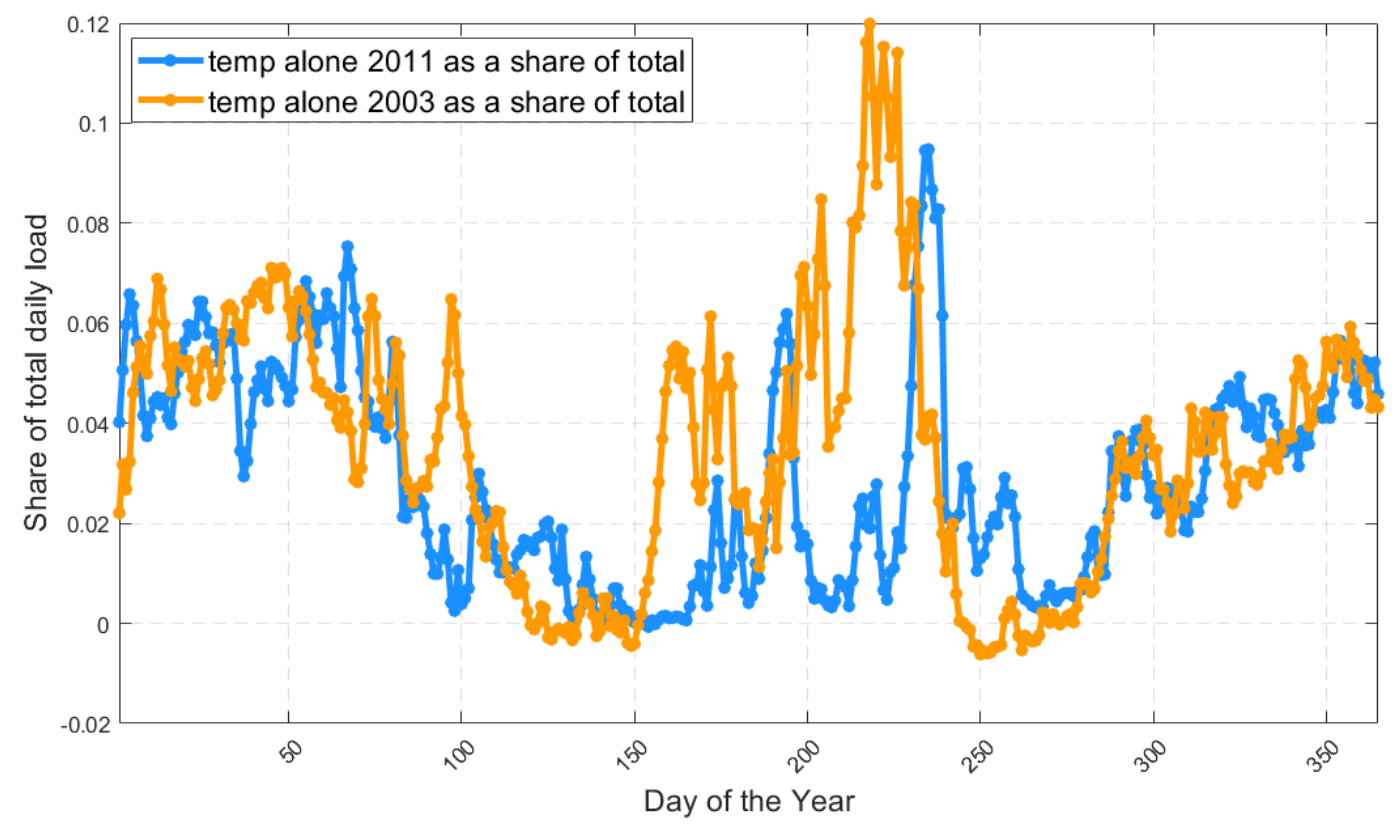




\section{Appendix A}

Table A.1. Selected coefficients from fitting equation (2) to samples constructed through various temperature selections and load aggregation (or selections). All regressions include our full set of household-by-time and time fixed effects. Standard errors are clustered at the household-day level. The temperature bins are dummy variables denoting whether the temperature falls in the indicated interval.

\begin{tabular}{|c|c|c|c|c|c|c|c|c|}
\hline & $\begin{array}{r}\text { 1-hour lo } \\
3: 00,6\end{array}$ & $\begin{array}{l}\text { at 0:00, } \\
\text {, etc. }\end{array}$ & $\begin{array}{l}\text { 3-hour loa } \\
\text { at beginni } \\
\text { hour inte } \\
\text { 0:00, 3:00 }\end{array}$ & $\begin{array}{l}\text { nd temp } \\
\text { of the 3- } \\
\text { (e.g., at } \\
00 \text {, etc.) }\end{array}$ & $\begin{array}{l}\text { 3-hour loa } \\
\text { at end of } \\
\text { interval (e } \\
\text { 6:00, 9: }\end{array}$ & $\begin{array}{l}\text { nd temp } \\
\text { 3-hour } \\
\text { at 3:00, } \\
\text { etc.) }\end{array}$ & $\begin{array}{r}\text { 1-hour lo } \\
\text { 1:00, } 2 \\
\text { (pref } \\
\text { specif }\end{array}$ & $\begin{array}{l}\text { 0:00, } \\
\text { etc. } \\
\text { ed } \\
\text { ion) }\end{array}$ \\
\hline & coeff & st err & coeff & st err & coeff & st err & coeff & st err \\
\hline $\begin{array}{l}\text { Holiday } \\
\text { dummy }\end{array}$ & 0.0112 & 0.0057 & 0.0204 & 0.0172 & 0.0278 & 0.0152 & 0.0086 & 0.0051 \\
\hline $\begin{array}{l}\text { Dark (share of } \\
\text { hour when it is } \\
\text { dark) }\end{array}$ & 0.0515 & 0.0038 & 0.2003 & 0.0112 & 0.1687 & 0.0108 & 0.0777 & 0.0038 \\
\hline-3.7 to $1.2^{\circ} \mathrm{C}$ & 0.0400 & 0.0132 & 0.0912 & 0.0304 & 0.0944 & 0.0230 & 0.0314 & 0.0095 \\
\hline-1.2 to $1.4^{\circ} \mathrm{C}$ & 0.0328 & 0.0075 & 0.0777 & 0.0159 & 0.0735 & 0.0095 & 0.0250 & 0.0034 \\
\hline 1.4 to $4^{\circ} \mathrm{C}$ & 0.0306 & 0.0091 & 0.0709 & 0.0197 & 0.0690 & 0.0157 & 0.0232 & 0.0053 \\
\hline 4 to $6.5^{\circ} \mathrm{C}$ & 0.0294 & 0.0083 & 0.0672 & 0.0193 & 0.0666 & 0.0159 & 0.0220 & 0.0052 \\
\hline 6.5 to $9.1^{\circ} \mathrm{C}$ & 0.0245 & 0.0090 & 0.0511 & 0.0214 & 0.0506 & 0.0177 & 0.0164 & 0.0057 \\
\hline 9.1 to $11.6^{\circ} \mathrm{C}$ & 0.0192 & 0.0088 & 0.0375 & 0.0213 & 0.0332 & 0.0179 & 0.0113 & 0.0058 \\
\hline 11.6 to $14.2^{\circ} \mathrm{C}$ & 0.0151 & 0.0092 & 0.0238 & 0.0220 & 0.0120 & 0.0188 & 0.0055 & 0.0061 \\
\hline 14.2 to $16.7^{\circ} \mathrm{C}$ & 0.0127 & 0.0094 & 0.0140 & 0.0226 & 0.0012 & 0.0195 & 0.0016 & 0.0063 \\
\hline 16.7 to $19.3^{\circ} \mathrm{C}$ & 0.0062 & 0.0094 & -0.0008 & 0.0228 & -0.0139 & 0.0200 & -0.0032 & 0.0065 \\
\hline 19.3 to $21.8^{\circ} \mathrm{C}$ & 0.0079 & 0.0095 & 0.0017 & 0.0232 & -0.0091 & 0.0205 & -0.0018 & 0.0066 \\
\hline 21.8 to $24.4^{\circ} \mathrm{C}$ & 0.0069 & 0.0097 & -0.0005 & 0.0240 & -0.0143 & 0.0216 & -0.0030 & 0.0070 \\
\hline 24.4 to $26.9^{\circ} \mathrm{C}$ & 0.0199 & 0.0102 & 0.0411 & 0.0259 & 0.0285 & 0.0237 & 0.0112 & 0.0077 \\
\hline 26.9 to $29.5^{\circ} \mathrm{C}$ & 0.0449 & 0.0136 & 0.1288 & 0.0378 & 0.1339 & 0.0361 & 0.0439 & 0.0119 \\
\hline 29.5 to $32^{\circ} \mathrm{C}$ & 0.0822 & 0.0180 & 0.2419 & 0.0515 & 0.2438 & 0.0502 & 0.0845 & 0.0169 \\
\hline 32 to $34.6^{\circ} \mathrm{C}$ & 0.1215 & 0.0259 & 0.3389 & 0.0765 & 0.3517 & 0.0741 & 0.1164 & 0.0250 \\
\hline 34.6 to $37.8^{\circ} \mathrm{C}$ & 0.1772 & 0.0422 & 0.4552 & 0.1259 & 0.5625 & 0.1311 & 0.1741 & 0.0417 \\
\hline constant & 0.2516 & 0.0091 & 0.7619 & 0.0226 & 0.7856 & 0.0184 & 0.2510 & 0.0063 \\
\hline Nobs & 8 per hou & old per & 8 per hou & old per & 8 per hou & Id per & 24 per hou & ld per \\
\hline
\end{tabular}

Note: The coefficients and standard errors in panels (B) and (C) must be divided by three to compare them with those in panels (A) and (D). 


\section{Appendix B}

Figure B.1 Temperature-electricity load curve for different temperature bin widths.
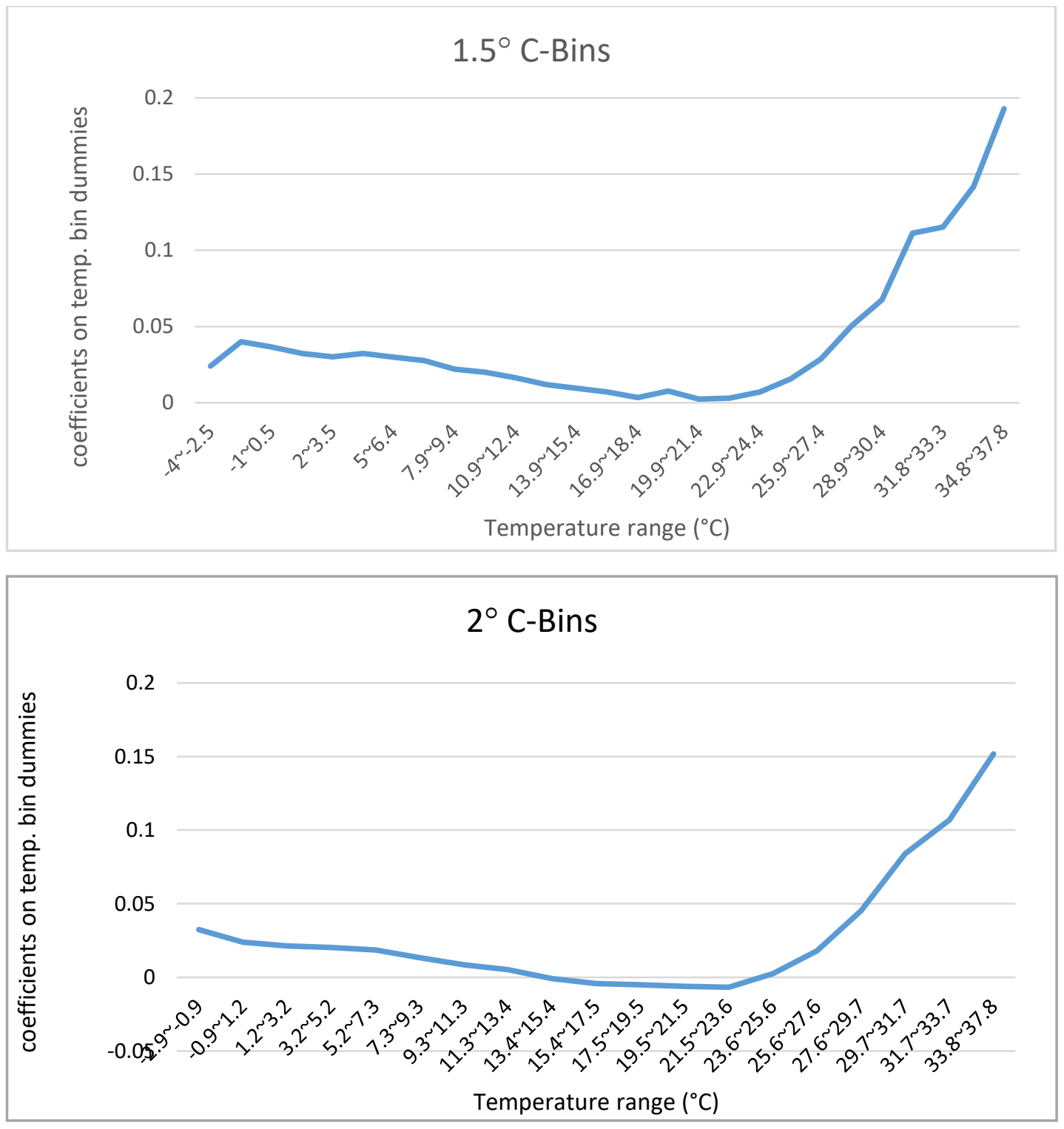


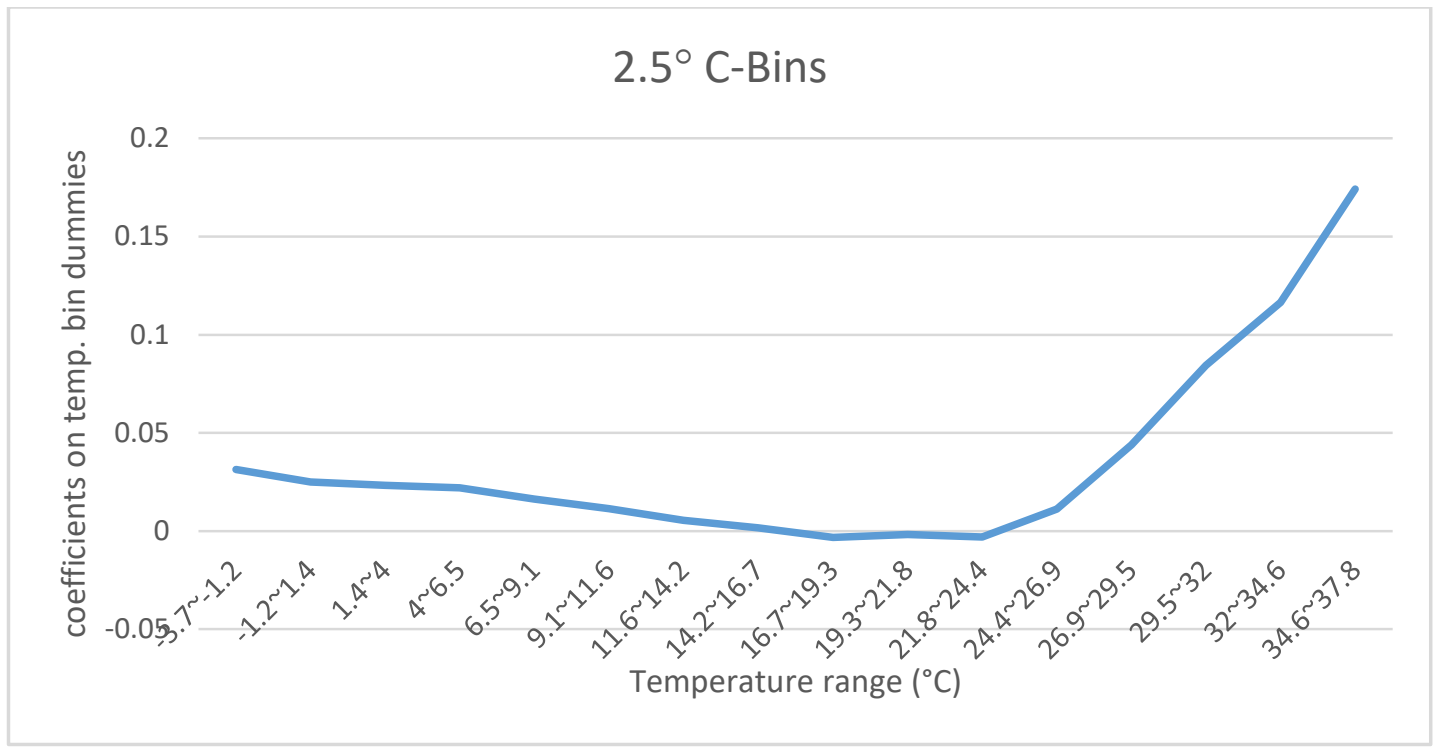




\section{Appendix C}

Figure C.1. Temperature-electricity load curve for different market zones in Italy.
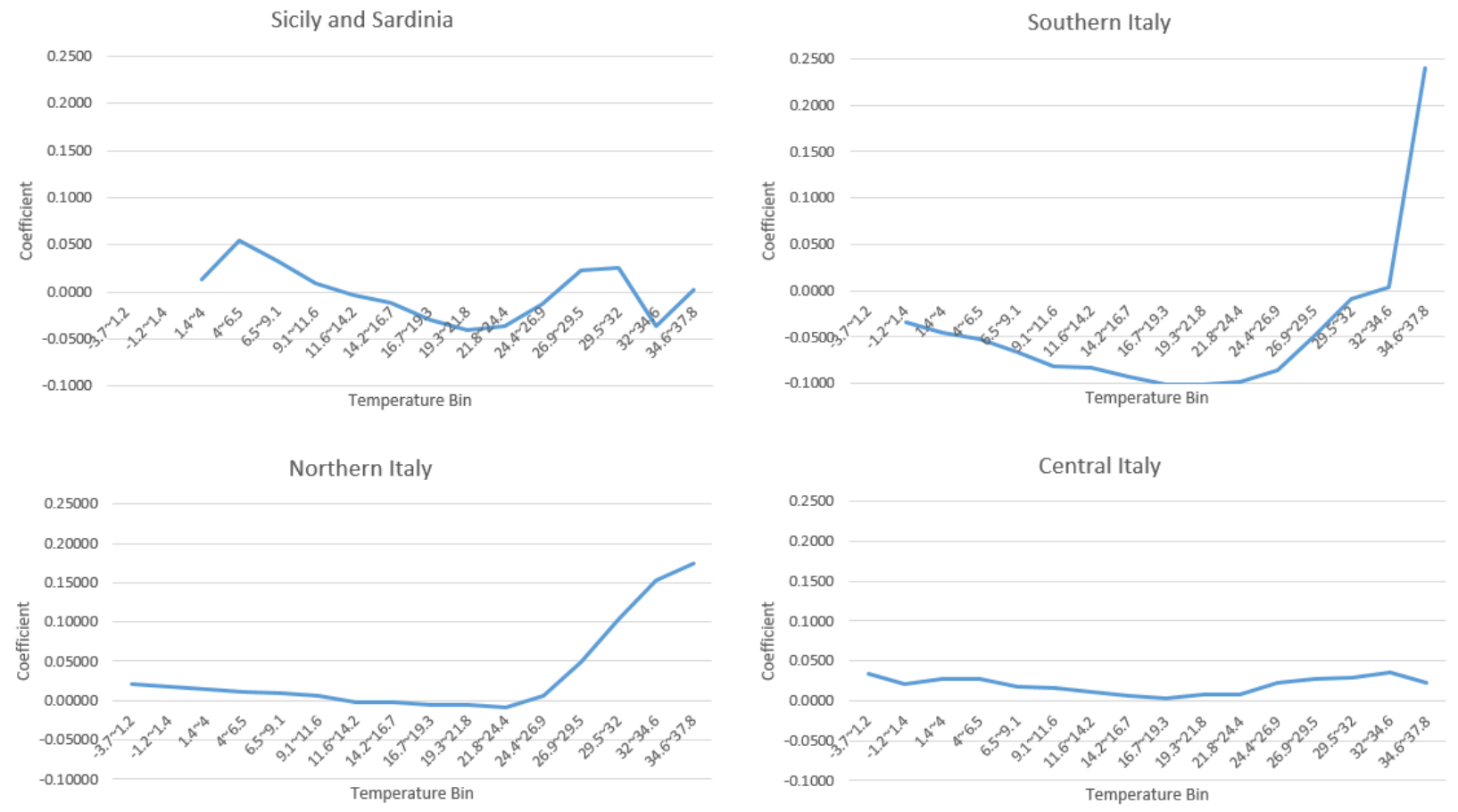
Appendix D. Temperatures in 2003 and 2011 (MERRA-2 data corresponding to the locations covered by our sample).

Figure D.1. Mean Daily Temperatures in 2003 and 2011.

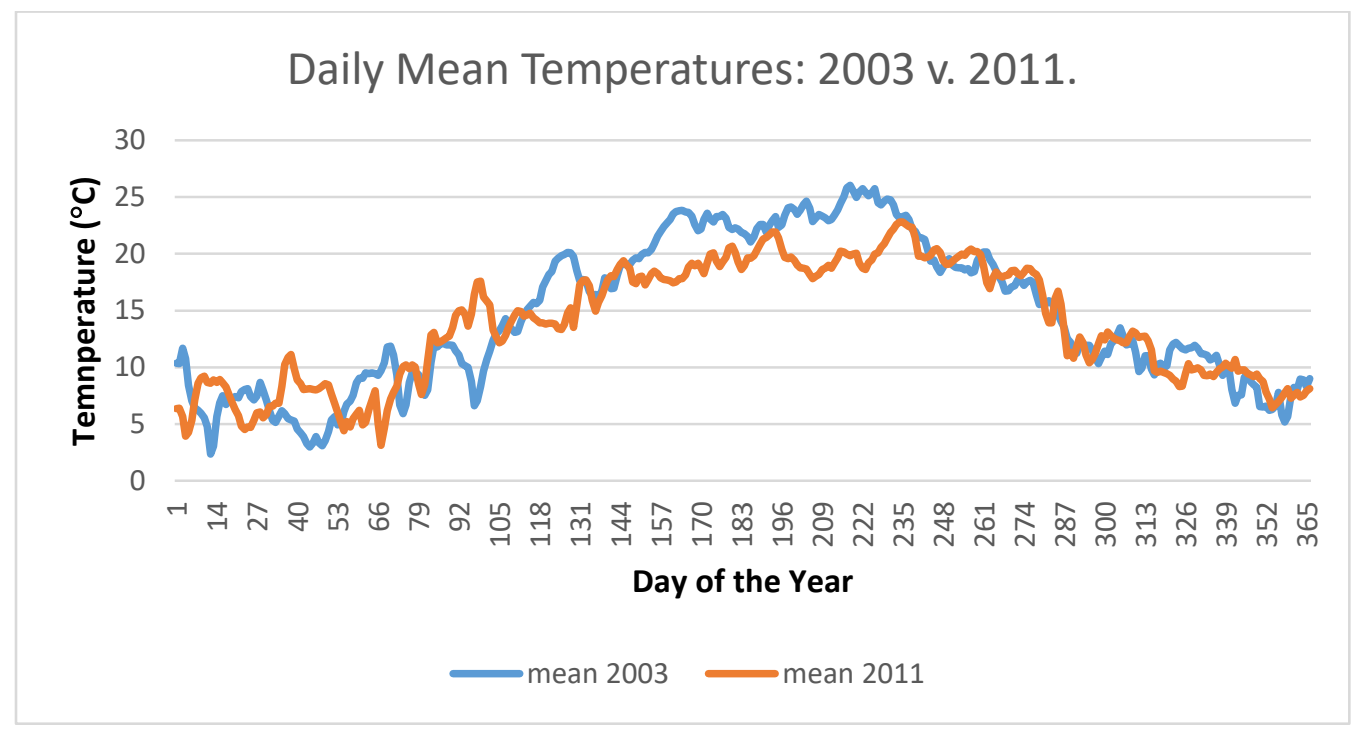

Figure D.2. Maximum Daily Temperatures in 2003 and 2011.

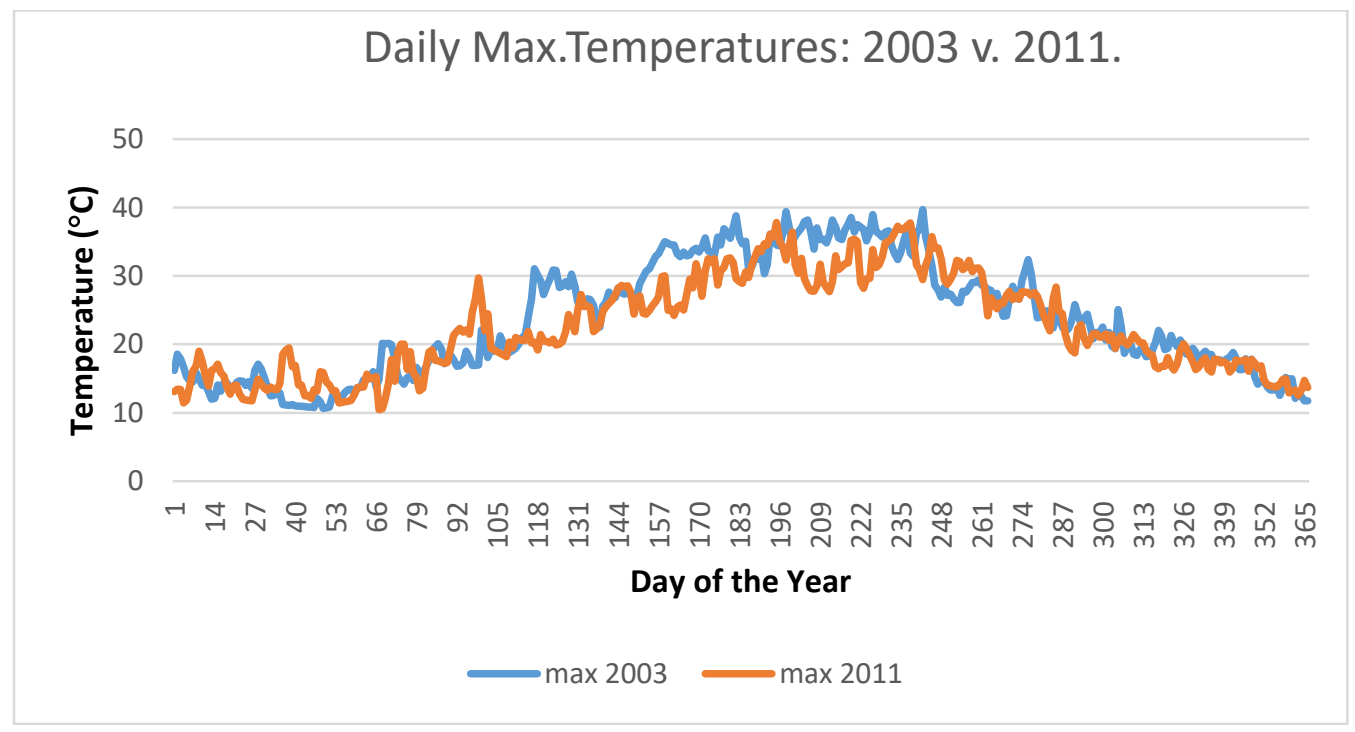

